\title{
Marginalidad y otredad en Cataluña (siglos XIV-XVI) ${ }^{1}$
}

\section{Marginality and Otherness in Catalonia $\left(14^{\text {th }}-16^{\text {th }}\right.$ centuries $)$}

\author{
Coral CUADRADA \\ MARC (Medical Anthropology Research Center). Universitat Rovira i Virgili \\ coral.cuadrada@urv.cat
}

Recibido: 01/09/2014

Aceptado: 23/01/2015

\section{RESUMEN}

Esta aportación se enmarca en una serie de nuevas reflexiones sobre temas ya tratados ampliamente por la historiografía, aunque admiten nuevos acercamientos. En especial me he esmerado en un esfuerzo teórico y conceptual en lo que se refiere a las categorías inherentes a lo marginal y a la otredad en Cataluña / Corona de Aragón (ss. XIV-XVI), utilizando como términos de comparación una serie de casos propios del Occidente europeo. El objetivo que pretendo en esta reflexión es el siguiente: abordar un tema amplio y ambicioso desde el enfoque multidimensional, diferenciando y repensando los factores distintivos de la marginalidad, y la otredad, como conceptos diferenciados, señalando el porqué de esas diferencias. Para ello he procedido a la consideración de la literatura científica española y extranjera, así como la utilización crítica de fuentes publicadas existentes y los datos e informaciones recabadas de la investigación de archivo, acompañados de los escritos de los pensadores de la época y las disposiciones legales emanadas de las ciudades. Este acercamiento debe encuadrarse en la perspectiva de la metodología de la antropología histórica y, en parte, de la actual historia cultural.

Palabras clave: otredad de edad y sexo, jurídica y del extraño; marginación física, económica, religiosa y moral.

\begin{abstract}
This contribution is part of a series of new reflections on themes that have already been widely dealt with by historiography, although new approaches are possible. Specifically a significant theoretical and conceptual effort has been made in this study regarding the categories of Marginality and the Otherness in Catalonia / the Crown of Aragon ( $14^{\text {th }}-16^{\text {th }}$ centuries), using as terms of comparison a series of cases from the European Occident. In this reflection I aim to approach a broad and ambitious subject from a multidimensional focus, to differentiate and re-think the diverse factors that make up Marginality, and Otherness as differentiated concepts, and indicate the reason for those differences. To this end I have examined Spanish and foreign scientific literature, as well as making critical use of existing published sources, data and information drawn from archival research, texts by the thinkers of the period and legal dispositions from the cities. This approach must be framed within the perspective of the methodology of historical anthropology and, in part, within current cultural history.
\end{abstract}

${ }^{1}$ Tema del cual realicé una primera aproximación años ha, CUADRADA, "Pobresa, marginació i sexe, p. 21-41. Amplío, reviso y actualizo la clasificación ofrecida entonces (que sólo enfoqué bajo la perspectiva de lo marginal). Fue una categorización ya entonces utilizada por los antropólogos, cfr. PraT i Carós, "Estigma", p. 125. 
Key words: age and gender otherness, legal and from the stranger, religious, moral, economic and physical marginalisation.

Sumario: 1. Introducción: sobre los conceptos y el método. 2. Otredad de edad y sexo. 3. Otredad jurídica. 4. Otredad del extraño. 5. Marginación física. 6. Marginación económica. 7. Marginación religiosa. 8. Marginación moral. 9. Últimas cuestiones conceptuales.

\title{
1. INTRODUCCIÓN: SOBRE LOS CONCEPTOS Y EL MÉTODO
}

\author{
Mas yo, que no estoy hecho para traviesos deportes \\ ni para cortejar a un amorosos espejo; \\ yo, que con mi burda estampa carezco de amable majestad \\ para pavonearme ante una ninfa licenciosa; \\ yo, cercenado de esa bella proporción, \\ arteramente despojado de encantos por la naturaleza, \\ deforme, inacabado, enviado antes de tiempo al mundo que respira; \\ a medias terminado, y tan renqueante y falto de donaire \\ que los perros me ladran cuando me paro ante ellos [...] \\ Y pues que no puedo actuar como un amante \\ ante estos tiempos de palabras corteses, \\ estoy resuelto a actuar como un villano \\ y odiar los frívolos placeres de esta época.
}

(Shakespeare, Ricardo III ${ }^{2}$ )

El tema de la marginación ${ }^{3}$ no es nuevo, tampoco lo son los estudios que la abordaron con mayor o menor fortuna, en las décadas de los ' 80 y ' 90 del siglo pasado, a mi

\footnotetext{
${ }^{2}$ Mi elipsis.

${ }^{3}$ De notable interés y todavía muy recomendables las obras clásicas de GeremeK, "Le marginal"; Inutiles au monde; y La potence ou la pitié. Un estado de la cuestión hasta el 2004 en Córdoba DE LA LlaVe, "Marginación social y criminalización", p. 293-322. Otra anterior en LADERO, "Grupos marginales", p. 505-601. Para Europa, desde el fin de la Edad Media y la incipiente industrialización RHEInHEIMER, Martín, Pobres, mendigos y vagabundos; Guesuin, D'ailleurs et de nulle part. Aportaciones bastante actuales a nivel peninsular y desde perspectivas multidisciplinares en las revistas Medievalismo, $\mathrm{n}^{\circ} 18$ (2008) sobre los marginados en la Edad Media, con colaboraciones de José Manuel Calderón Ortega, Ana Echevarría Arsuaga, Luís Martínez García, Isabel Montes Romero-Camacho, Cristina Segura Graíno y Felix Segura Urra; y Clío \& Crimen, $n^{\circ} 9$ (2012), coordinada por Iñaki BAZÁn, con el título "En el umbral del delito: marginados y excluidos de la sociedad medieval, con artículos de $\mathrm{M}^{\mathrm{a}}$ Isabel del VAL VALdivieso, Lucía LAHOz, Ricardo Córdoba DE LA Llave, María del Carmen García Herrero, Mercedes Gallent Marco, Rafael Narboba Vizcaíno, Jesús Ángel Solórzano Telechea, José Ángel Lecanda Esteban y Leticia Tobalina Pulido, y Martha Fabiola García Álvarez. Sobre la exclusión-represión, delito y pecado, $c f r$. el análisis de la historiografía de CóRDOBA DE LA LLAVE, donde hace una valoración de las aportaciones relativas a los años entre 1990 y 2011, tanto de jornadas y encuentros como de estudios de historiadores/as particulares, especialistas de época medieval y moderna; así como la recopilación bibliográfica de Medel MarchenA, ambos en Los caminos, p. 15-19 y p. 509-543. Respecto a la identificación entre pecado y delito todas las aportaciones en LóPEZ OJEDA (coord.), Los caminos de la exclusión, 2012. Ricardo CÓRDOBA DE LA LLAVE, en la más reciente puesta al día historiográfica sobre conflictividad en la Edad Media, con referencias muy interesantes a temas aquí tratados, revisa publicaciones muy relevantes de los últimos cuarenta años; resalto la atención a la conflictividad socio-política urbana, la persecución a las minorias religiosas; y a las tendencias que el autor considera como más novedosas de los úl- 
entender como resultado de los anteriores análisis respecto a la pobreza que inauguró Michel Mollat ${ }^{4}$ unos veinte años antes. Según mi opinión, de marginalidad strictu sensu es difícil hablar antes de finales del siglo XIII o principios del XIV, cuando se da el fenómeno que Frantisek Graus ${ }^{5}$ tituló como la topología del miedo, y de ella las consecuentes prácticas de exclusión -topografía de lo diferente visto desde la óptica de la distribución del espacio urbano. En este sentido, insistía sobre la exclusión urbanística: juderías, morerías, burdeles, leproserías. Luego señalaba la necesidad de homogeneización social y de eliminación paulatina de grupos-otro, incorporando en los discursos del poder -cívico, teológico, jurídico- de la otredad asimilándola al demonio, o a los otros interiores de la sociedad medieval captados con brillantez años más tarde por Josep Fontana ${ }^{6}$. Estos conceptos -marginación, exclusión, alteridad-al haberse confundido entre sí y, por lo tanto, haberlos aplicado indiscriminadamente al análisis histórico, es lo que ha conllevado la imposibilidad de discernir netamente entre sus significados. Mi intención es, pues, reflexionar sobre ellos definiendo para cada cual sus características, a fin de poder proceder a la necesaria distinción y categorización.

En términos generales, el concepto de marginado en los escritos medievales tiene varias acepciones. En sentido concreto abraza un conjunto muy amplio de personajes -trotamundos, indigentes, miserables, desterrados, herejes y disidentes religiosos, judíos y musulmanes, leprosos, prostitutas, extranjeros...-, pero también se ha incluido, desde una perspectiva más vasta, grupos tan poco minoritarios como las mujeres, los labradores, los viejos o los niños ${ }^{7}$. Si lo hiciéramos así, nos encontraríamos ante el hecho de que el noventa por ciento de la población quedaría comprendida en el concepto de marginación, hecho que, sin duda, resultaría, además de excesivo, casi desconcertante ${ }^{8}$. Por si todo esto no fuera suficiente, todavía podemos entrever otros problemas inherentes a la aplicación de una perspectiva única de interpretación. Por ejemplo, todo el mundo ve claro que el hereje y el miserable son excluidos, pero ¿qué relación puede existir entre un noble cátaro y un pobre de solemnidad? Un apóstata es otro marginado paradigmático, porque la apostasía era duramente castigada y significaba la voluntad explícita de apartarse de la universitas christianorum. Ahora bien,

timos tiempos, entre ellos los conflictos urbanos de naturaleza no política o la marginación social, $c f r$. CóRDOBA DE LA LLAVE, "Conflictividad social", p. 34-53.

${ }^{4}$ Mollat decía que el indigente era el que se encontraba en toda situación de debilidad, dependencia o humillación que le privara temporal o permanentemente de medios de poder y consideración social, $c f r$. MolLat, Les pauvres au Moyen Age, 1978.

${ }^{5}$ Graus, Frantisek, "Randgruppen der städtischen Gesellschaft", p. 385-437. Hay estudios más recientes que han reflexionado sobre el margen físico y la marginalidad, relacionando hombre y espacio -frontera territorial, frontera social-, las figuras y colectivos al margen, o arte y representación del marginado, $c f r$. MoNTEIRA Arias, Muñoz Martínez, Villaseñor Sebastián, Relegados al margen.

${ }^{6}$ Fontana, Europa ante el espejo, p. 56-88. El autor parte del concepto del Otro como recurso para la construcción identitaria de Europa. Son Otros los bárbaros, los infieles, el Islam, Oriente... unos Otros que aquí no tomo en consideración, al no referirme a Europa en su conjunto, sino a las sociedades, campos y ciudades bajo y post medievales catalanas, es decir, el foco de análisis es mucho más reducido.

${ }^{7}$ Ladero opina que el concepto de marginalidad demanda el complemento de minoría, LADERO, op.cit., p. 505. Evidentemente, si somos estrictos/as, así debería de ser.

${ }^{8}$ Es debido a la confusión entre otredad y marginalidad, una no es sinónimo de la otra, ni ha de implicarla, ni siempre ni obligatoriamente. 
¿así fue considerado fray Anselm Turmeda, a quien reyes y papas suplicaron que volviera a la cristiandad? Después había los auto-marginados - pobres voluntarios, eremitas, franciscanos- ¿es correcto encerrarlos junto a los marginados por decisión propia, teniendo en cuenta que alguno de ellos llegaría a ser rey, como Ramiro II Monje o el niño Felipe de Mallorca? También había una marginación que podía ser temporal -forasteros, pobres-y una de permanente -judíos, musulmanes-, aun así, hay grupos que disfrutaban de una situación intermedia, como los libertos y los conversos. En cambio, la otredad es siempre absoluta, no acostumbra a admitir estados intermedios, menos aún en la época que estudio. El otro sexual al hombre es la mujer; por edad el otro al adulto el niño o el viejo; por raza, el negro al blanco.

Decía Emilio Mitre que el excluido, el marginado, es aquel que viene definido por su inutilidad social y, por tanto desprotegido, inadaptado y rechazado 9 . Conceptualmente la marginalidad es consecuencia de la discriminación por lo que hace al acceso al capital cultural, aunque no necesariamente está fuera del orden social. Se hace necesario distinguir también entre marginación y exclusión. Las mujeres, por ejemplo, están marginadas pero no excluidas, se las incluye de manera que quedan subsumidas en el orden patriarcal pero, dentro de este, cumplen un rol reconocido. La marginalidad podría estar formada por grupos más o menos homogéneos, con signos identitario ${ }^{10}$ más o menos definidos, mientras que la exclusión es solo la consecuencia de afirmarse en la norma en relación al otro. La exclusión no supone una identidad, aunque el poder la empuje a adquirir una (el migrante no constituye un colectivo homogéneo, ni el loco, por ejemplo). Por tanto, la exclusión social puede entenderse como la incapacidad de tomar parte activamente de una sociedad como consecuencia de la negación de su estado o circunstancia. En cambio en la categoría de marginación cabe incluir la noción antropológica de minoría, en el sentido de que existe dentro del grupo un conjunto de prácticas que los identifican y que, en cierta manera les permite desarrollarse de forma organizada y preservar prácticas propias -judíos, musulmanes ${ }^{11}$. El/la excluida, al contrario, no se organiza, de hecho es consecuencia de una identidad creada desde fuera, lo que Foucault ejemplifica en el paso de infractor a delincuente ${ }^{12}$, donde el segundo deviene una identidad que determina el sujeto y lo hace susceptible de ser controlado, adiestrado y/o dirigido.

Vista la complejidad de la marginación medieval y moderna y su confusión a veces con la otredad ${ }^{13}$ es necesario, consecuentemente, intentar una clasificación capaz de

\footnotetext{
${ }^{9}$ Mitre, "Historia y marginación", p. 19.

${ }^{10}$ Sobre identidad, las últimas publicaciones colectivas, cfr. SABATÉ (ed.), Hybrid identities, y Identities on the move, 2014, aunque el concepto de identidad vs. alteridad de Sabaté no es el que pueda servir aquí, dado que se refiere en general a las elites, no a los más desfavorecidos, objetos de mi estudio.

${ }^{11}$ Agradezco a Enric Olartecoechea las sugerencias, fruto de un diálogo ininterrumpido y fecundo.

${ }^{12}$ Foucault, Vigilar y castigar, p. 83.

${ }^{13}$ Son conceptos complejos y que, en ocasiones, pueden confundirse. El de marginación y/o exclusión ha sido ampliamente estudiado por la historiografia, como ha quedado evidenciado en la nota 4 . El de otredad menos, y algunas veces aplicado sin matiz conceptual estricto a grupos sociales que también sufrieron exclusión y que a partir de coyunturas desfavorables podemos considerar ya marginales, $c f r$. por ejemplo Monsalvo Antón, "El enclave infiel", p. 171-223 (judíos) ; y Mitre FernÁNDEZ, "El enclave hereje", p. 225-244 (herejes). Según los autores el judío o el hereje fue un Otro del cristiano. Esta utilización parcial del concepto se repite en el apartado titulado "El pecado y "el otro", en el libro colectivo Pecar en la Edad Media, donde se consideran
} 
ordenar en categorías que, a pesar de no ser cerradas ni absolutas, porque pueden solaparse unas a otras, nos ayudarán a entender con mayor facilidad ese espinoso y difícil mundo. No pretendo con ello delimitar los conjuntos sociales sistematizándolos absolutamente, ni fijarlos de forma arbitraria en un ámbito cerrado, lo que no les convendría para nada ni se adecuaría en absoluto a la realidad histórica. Si algo define a los y las excluidas es la movilidad, la fluidez. O quizá todo lo contrario, si entendemos la exclusión como la rigidificación de la fluidez en categorías inflexibles aplicadas a la fuerza - a la prostitución, por ejemplo.

Los objetivos que pretendo en esta reflexión son los siguientes: en primer lugar, abordar un tema amplio y ambicioso desde el enfoque multidimensional, diferenciando y repensando sobre los factores distintivos de la marginalidad, y la otredad, como conceptos diferenciados, señalando el porqué de esas diferencias. He procedido a la consideración de la literatura científica española y extranjera ${ }^{14}$, así como la utilización crítica de fuentes publicadas existentes y los datos e informaciones recabadas de la investigación de archivo, acompañados de los escritos de los pensadores de la época y las disposiciones legales emanadas de las ciudades. El marco espacial escogido constituye una muestra de análisis correspondiente al territorio catalán / Corona de Aragón, incrementándola con términos de comparación por una serie de casos propios del Occidente europeo. El marco temporal es el de la Baja Edad Media y la Primera Edad Moderna: del siglo XIV al XVI. La estructura interna del trabajo está planteada desde el binomio conceptual otredad/marginalidad, mediado por el de exclusión. Analizo para el primer concepto la otredad de edad y sexo, jurídica, y de lo extraño. El segundo concepto contempla cuatro tipos de marginación, que ordeno según el grado de implicación voluntaria en la exclusión, de menor a mayor: así se tratará la marginación física, económica, religiosa y moral. Este acercamiento debe encuadrarse en la perspectiva de la metodología de la antropología histórica y, en cierto modo, recaba algunas categorías metodológicas de la actual historia cultural ${ }^{15}$, al plantear problemas de difusión de imágenes de determinados grupos sociales entre las formulaciones cultas y las percepciones populares.

\section{OTREDAD DE EDAD Y SEXO}

Empiezo por la alteridad por razón de edad y sexo, la más evidente, inmediata y fácil de comprender. No creo que pueda entenderse la infancia, en general, como una etapa de exclusión. Ni tampoco que sea correcto repetir lo que en los '60 afirmó Philippe Ariés ${ }^{16}$, la no existencia de la infancia como tal en la Edad Media, que tantos estu-

\footnotetext{
"otros" a herejes, judíos y musulmanes, como si la alteridad fuera sólo religiosa. El concepto de otredad que formulo en estas reflexiones amplía y matiza estos planteamientos.

${ }^{14}$ Dado el enfoque pluritemático abordado, el aparato crítico es nutrido. Sin embargo, no ha sido mi intención dar cabida a todos los debates historiográficos existentes en cada una de las categorías analizadas, lo que convertiría un ensayo teórico en una revisión bibliográfica. Por esta razón he incluido las obras clásicas o los estudios recientes que amplían y/o sustentan las ideas expresadas en el texto y las propuestas explicativas más actuales, sin ambiciones de exhaustividad.

${ }^{15}$ Obligada la cita a BuRKe, Peter, What is cultural history?, 2008; y Hibridismo cultural, 2010.

${ }^{16}$ ArIÈs, L'Enfant et la vie familiale; idem, "La infancia", p. 5-17.
} 
dios, a favor o en contra generó; no es mi intención terciar al respecto ni tampoco abriga ningún interés para el tema que analizo. La infancia era un período de la vida -a veces simbolizada con el mes de enero-, una etapa transitoria y corta que distaba mucho de ser considerada como importante. Tal vez esa indiferencia venía de la gran mortalidad, que aumentaba en los años de hambres y pestes: aproximadamente el 80 $\%$ en los menores de 18 años de los grupos urbanos más pobres moría. Los que sobrevivían accedían muy pronto al mercado laboral, documenté contractos de servicio doméstico para niñas de cinco años, y de aprendices de siete ${ }^{17}$. Llull indica, entre las obras de misericordia de Evast y Aloma, que a los fadrinets chichs orfenets posaven a alguns officis, per tal que, quant fossen grans, per pobrea no fossen ocasionats a peccar $^{18}$. Porque tremendo problema era el de los expósitos, condenados en principio a la marginación desde el nacimiento.

Fueron las grandes ciudades italianas, Florencia y Roma, en primer lugar, las que idearon una solución destinada a difundirse por toda Europa: los hospicios o casas de expósitos para la acogida de niños abandonados, como fue el hospital de la Santa Cruz en Barcelona ${ }^{19}$. Nacidas a veces de fundaciones privadas, pero más bien por iniciativa de las autoridades locales, y mantenidas por las finanzas municipales, estas instituciones acogían los niños que antes se abandonaban en espera de la piedad de los desconocidos en las puertas de los conventos e iglesias. Existen referencias que indican la causa del abandono por la extrema pobreza de los padres, en una nota de una niña se escribe que es hija de matrimoni e són tan miserables que no és en dir...; otro va acompañado de que sus padres són pobres com Job, y explican que ya tienen mucha prole, la madre está a punto de dar a luz y no tiene leche para amamantar al pequeño. Estas situaciones dramáticas se agudizan todavía más cuando el padre está ausente por cualquier razón, o en el caso de mujeres completamente solas. Vicente Ferrer animaba en sus sermones a los ricos a emplear sus bienes en fer moltes almoynes a pobres, a òrphenes, spitals, etc., y elogiaba a aquellos prelados que destinaban una porción de sus rentas a sostener pobres, òrphenes, spitals ${ }^{20}$. Eiximenis, citando a Boecio, ensalzaba a quien adoptaba a un huérfano: aquest mèrit e guardó dóna Déu per excel-lència gran a aquells qui per amor sua affillen, e informen, e sostenen los orfens e pobres e desemparats. Y afirmaba:

E per tal antiguament les grans dones cant volien ab Déu inpetrar que.ls donàs infants o que.ls donàs vida a aquells que havien e que.ls feés bons, prenien dels espitals o d'algunes persones pobres alcun infant que elles metexes nodrien e affillaven, axí com si fossen lurs ${ }^{21}$.

En cuanto a los viejos y a las viejas, quien más habla de ellos es de nuevo Vicente Ferrer, aunque su descripción no es precisamente halagadora, la única virtud que les atribuye, para nada despreciable, es la de la "sabiduría". En 1236 Roger Bacon publi-

${ }^{17}$ CUADRAdA, "Sobre les relacions camp-ciutat", p.178-183.

${ }^{18}$ Llull, Libre de Evast e Blanquerna, I, p. 29.

19 Rubio Vela, Agustín, "Infancia y marginación”, p. 111-153; idem, "La asistencia hospitalària...”, p. 159-191; GonZÁlez BetLinski, Vinyoles VidAL, "Els infants abandonats", p. 191-285.

${ }^{20}$ FerRer, Sermons, I, p. 90.

${ }^{21}$ EIximenis, Lo libre de les dones, I, p. 28. 
có la obra La cura de la vejez y el rejuvenecimiento y la preservación de la juventud. Bacon entendió la vejez como un castigo divino, causa del pecado original, según la teoría de los humores, fría y húmeda, en contraste con la juventud, cálida y seca. Aunque repitió creencias aristotélicas, declaró que la demencia era inevitable después de un tiempo suficiente de vida, y señaló que el cerebro era el centro de la memoria y el pensamiento, no el corazón como entonces se suponía. La gerontología medieval avanzó, hay abundantes textos que se conocen con el nombre de "regímenes de salud", en los que se aconseja que los ancianos deben tomar cierto tipo de alimentos y huir de otros. En cualquier caso se trataba de remedios a los que los viejos acomodados podían disfrutar mucho mejor que los de condición modesta. En el transcurso de la época medieval se puede establecer una cierta cronología de las actitudes adoptadas ante la vejez. Diversos historiadores afirman, con argumentos creíbles, que en los siglos XIV y XV se dio una recuperación de la idea de la vejez ${ }^{22}$. El acontecimiento crucial de la Peste Negra cambió las actitudes sociales, porque la enfermedad fue más virulenta con los niños y jóvenes ${ }^{23}$. Por ello la estructura familiar mutó, la autoridad y el poder se concentró en las manos de los ancianos, los lazos afectivos también, amén de los matrimonios con diferencias de edad de 20-30 años, y de 50-60 entre padres e hijos. La mentalidad social varió y la senectud se convirtió en una edad con funciones y necesidades específicas. Prudencia y de sabios era prevenir en la juventud de cara a la vejez, donde se resaltaba con claridad que lo peor era llegar a pobre y viejo:

\section{De prudència}

En tanto que moço fueres / deves de tomar consejo / para quando seas viejo / si buena vejez quisieres: / Mas la vida muy ociosa / que tuvieres muy sabrosa / mientras gozares el día, / suele ser la triste guía / de la noche tenebrosa. / Que durante juventud / súfrese qualquier cuidado, / mas ay del triste cargado / de pobreza y senectud: / mas nuestro seso soez / es en esto mal juez, / que por su gran ceguedad / poco vee la moce$\mathrm{dad} /$ los males de la vejez ${ }^{24}$.

La debilidad y la indiferencia eran las características intrínsecas que san Isidoro atribuía a la vejez ${ }^{25}$. Guillermo el Mariscal, después de una vida militar intensa, declaró de sí mismo: "Soy demasiado viejo, débil y estoy completamente averiado ${ }^{26 "}$ " ¿Qué dijo Felipe de Novara? pues que tuvieran mucho cuidado los ancianos y que no incurrieran en el terrible error de casarse con una mujer joven, porque indefectiblemente serían engañados. Hay testimonios casi personales, muy de fines del Medievo, como el de un anciano que habló por sí mismo, Jean Regnier, en 1460, quien se quejaba de haber llegado a una edad en la que tenía moquillo en la nariz, carecía de dientes, sus alimentos eran leche y sopas, estaba forrado de pieles y llevaba esclavina, todo el día se lo pasaba junto al fuego y las manos le temblaban. También es bastante personal la opinión del flamenco Jean Molinet, que data del año 1500. Dice: "tengo

${ }^{22}$ Minois, Historia de la vejez; Homet, Los viejos y la vejez; García Herrero, "Las etapas”, p. 29-48.

${ }^{23}$ Homet, Los viejos y la vejez, p. 47-48.

${ }^{24}$ Guzmán, Decreto de Sabios, p. 60.

25 Pérez de Tudela y Velasco, “Ancianidad, viudedad”, p. 285-316; Valdeón, "El ritmo del individuo", p. 275-288.

26 Duby, Georges, Guillermo el Mariscal, Madrid: Alianza, 1997, p. 4. 
los cabellos blancos, la voz muy débil, he perdido la vista en un ojo, la inteligencia está averiada y, lo más terrible, tengo impotencia sexual". Cuando se habla de mujeres ancianas se suele decir de ellas que son celestinescas y que lo principal que tienen son mañas más o menos brujeriles, únicas facetas para las que sirven en este mundo. Es evidente que las brujas ${ }^{27}$-viejas o jóvenes- eran miradas de soslayo, temidas, excluidas, acusadas y asesinadas, proceso que como se sabe irá en crescendo desde la Baja Medievalidad hasta el siglo XVII.

Los Usatges de Barcelona explicitan de una manera particular la inferioridad por razón de sexo, según nuestra forma de ver actual. El usatge titulado Unaqueque mulier hace constar que toda mujer será enmendada -se entiende, si ha caído en falta- según el valor de su marido, y si no tiene, según el valor de su padre o de su hermano. Dependencia y definición de la mujer en relación al hombre, por lo tanto. Pero pretender presentar las mujeres como un grupo social marginado exige algunas puntualizaciones. No todas las mujeres, solamente por el hecho de serlo, entraban en la marginalidad, sino que entre ellas había notables diferencias ${ }^{28}$. Por ejemplo Ermessenda, condesa de Carcasona, la cual reinó en el casal de Barcelona en vida del marido, del hijo y del nieto. Cada vez que alguien le cuestionaba el poder, respondía simple, pero contundente: "devolvedme la dote", hecho que el incipiente condado no se podía permitir. Ermessenda sólo era una mujer, ahora bien, ¿cómo compararla con una jornalera humilde, de remensa, sujeta a los malos usos? ¿O con la sirviente doméstica, alejada del hogar paterno por miseria? ¿O con aquella hija de menestrales que igualmente había de irse fuera de casa, a un lugar extraño, por carencia de recursos? O más todavía, ¿con la esclava raptada en Ultramar, vendida en los mercados occidentales, recibida en el ámbito doméstico como signo de distinción y, más tarde, liberada y abandonada a su suerte en momentos de hambruna y carestía? Emancipación que quizás obedecía a un par de objetivos maliciosos: por un lado, echar fuera a una persona sospechosa de estar embarazada del amo -hecho muy común en la época- o, del otro, el ahorrarse alimentar una boca más. ¿El destino de esas esclavas?... Es una obviedad, en muchos casos era la prostitución. Las mujeres, pues, formaban un colectivo extraordinariamente diverso, el cual ni era minoría social ni ha de ser considerado marginal, sino la alteridad masculina por excelencia ${ }^{29}$.

${ }^{27}$ GuAL VILÀ, Justícia i terra, p. 40-41, Armari II, calaix 4, doc. 3: acusación a Margarita, mujer de Joan Pere, quien haurie maleficiats als predits Franci Capafons e a Ursola muller sua en tanta manera que los dits Franci e Ursola cóniuges la primera nit e altres no se són coneguts carnalment per los maleficis e encantaments fets per la predita Margarita e dita Margarita haurie donat metzines al dit Franci Capafons, per les quals ere tornat orat e stave fora de seny. (19.11.1500). Idem, p. 108, Armari II, calaix 9, doc. 19: proceso y condena a muerte en la horca a Francina Redorta, viuda, per bruxa e metsinera, (3.10.1616).

${ }^{28}$ La bibliografía sobre mujeres en la edad media es notable y se encuentra en continua revisión. No me parece pertinente incluir aquí un estado de la cuestión sobre este aspecto porque mi reflexión no se refiere a la evaluación historiográfica; véase una aportación reciente que recoge los debates metodológicos actuales en del VAl VAldivieso, “La historia de la mujer..." p. 19-40.

${ }^{29}$ No es posible, por motivos de economía de espacio, desarrollar aquí la misoginia de los siglos XIV-XV, este es un tema que merece un tratamiento aparte. Misoginia no es sinónimo de marginación. Para estudiar a las mujeres medievales se debe de hacer desde intersecciones varias, no sólo y únicamente desde la perspectiva del género, en exceso reduccionista y anacrónica. 


\section{OTREDAD JURÍDICA}

En segundo lugar, existía una alteridad que algunos autores han llamado jurídica, refiriéndose a los esclavos y a los siervos de la gleba. Una alteridad, a mi entender, que significa un desplazamiento de la mismedad en otra entidad o grupo social, pero no supone exclusión ni marginalidad alguna. En lo concerniente al campesinado, ha de sumarse una cierta discriminación cultural, sobre todo desde las élites intelectuales y/o aristocráticas, aspecto muy común en las relaciones con el otro, al cual se considera con frecuencia como un inferior. En los Usatges de Barcelona se designa a los villanos como los que "no poseen otra dignidad que la de ser cristianos ${ }^{30}$ ", lo cual indica un cierto estatuto mínimo conferido por la religión. A partir del Doscientos el desarrollo de la servidumbre afectó a los campesinos libres, violando una libertad modesta, pero fundamental. La justificación de la sujeción implicaba la privación de derechos, no una relación económica entre el señor y el remensa; la injusticia de la dominación arbitraria fue entonces patente, de forma notable en el contexto socioeconómico hostil que siguió a la gran Peste de $1348^{31}$. Así, en Cataluña, como en Alemania, las reivindicaciones sobre la condición del campesinado se centraron en la servidumbre, que se estimaba violación de la ley divina y natural. Una manera de defender la sumisión era considerar que los labradores estaban creados para ser tratados de esa manera, de ahí la comparación con los animales. Burlarse pesadamente de los campesinos y compararlos a criaturas infra-humanas era un tema común en toda Europa, en especial en el Imperio, donde se convirtió en algo tremendamente popular, un género de sátira dirigida hacia la estupidez y la materialidad natural de las gentes del campo, pintura negativa que encontrará su lugar de representación en el arte y se mantendrá con vigor hasta el siglo XVII ${ }^{32}$. Se consideraba entonces que no se ganaba nada tratándolos bien, como decía una poesía muy difundida: Rustica gens est optima flens et pessima ridens [o gaudens] ${ }^{33}$. Otro proverbio sostenía que los villanos, los asnos y los avellanos se parecían porque si no se les golpeaba eran inútiles ${ }^{34}$.

La descripción del campesino en términos de animalidad comportaba características que, ligadas a una sub-humanidad, excusaban los malos tratos. Ciertos discursos invocaban la metáfora de la productividad; como que los labradores respondían a otros parámetros, el único modo de obtener algo de ellos era hacerlos trabajar como

${ }^{30}$ Usatges de Barcelona, cap 11, us. 13, p. 60: Rusticus interfectus seu allus homo qui nullam habet dignitatem preter quod christianus est emendetur per VI uncias.

${ }^{31}$ Freedman, The Origins of Peasant Servitude, p. 189-202. No quiero decir con ello que no existiera servidumbre anteriormente, al contrario, como demostré fehacientemente en mi tesis doctoral tiempo ha, $c f r$. CUADRADA, Coral, El Maresme Medieval: Hàbitat, Economia i Societat, segles X-XIV, Mataró: Caixa d'Estalvis Laietana, 1988, p. 600-635, refrendada por estudios posteriores, cfr. To FiguERAs, Família i Hereu, p. 344-347; Lluch Bramon, Els remences, p. 409-415; SABATÉ, La feudalización, p.243-252. Lo que indico y comparto con Freedman es la arbitrariedad y el recrudecimiento de la punción señorial como uno de los efectos de la epidemia, antesala de las revueltas remensas, $c f r$. SALRACH, "La pesta negra", p. 13-34.

32 RAupP, Bauernsatiren; Entstehung und Entwicklung des bäuerlichen Genres; MiEdEMA, "Realism and Comic", p. 205-219; Moxey, Peasants Warriors and Wives, p. 35-66; HüGLi, Der deutsche Bauer im Mittelalter, p. 97-141; Jöst, Bauernfeindlichkeit.

33 Proverbia, 4, no 26997.

34 Rusticus ac asinus, nux, hec tria connumerata non faciunt fructum, fuerint nisi combaculata, Proverbia, $4, \mathrm{n}^{\circ} 27016$. 
bestias de carga. Otro argumento consistía en decir que eran sucios y apestosos como las bestias ${ }^{35}$. A pesar de todo, la metáfora animal no era en sí degradante, los nobles podían ser considerados "fieras salvajes", pero es cuando el discurso de la animalidad se usa no como metáfora, sino en oposición a la humanidad, que la hostilidad hacia los campesinos se hace más que evidente. Eiximenis decía que la quinta raíz de malicia era la rusticidad y payesía, a los labradores los equiparaba a los locos:

per tal quant són bestials e rústecs e orats e sens raó, e quaix bèsties brutes e fort malicioses. Per tal, de la bestialitat los ve no entendre raó, e de no entendre raó los ve tot llur mal; e d'aquesta bestialitat los ve, per consegüent, que es pensen que tot hom los vulla enganar; e d'aquest cuidar los neix e.l cor terrible malícia, volent-se sots ella cobrir e ab ella defensar ${ }^{36}$.

Otra forma de servidumbre era la esclavitud ${ }^{37}$, fácil de excusar o ignorar, porque estaba vinculada a la propiedad de los no-cristianos. En el ocaso de la Edad Media y en los primeros tiempos de la Modernidad, el poder económico, en el norte de Italia, opinaba y declaraba que bautizar un esclavo sería el sinónimo de bautizar un buey o cualquier otro animal; mientras que, por parte de la Iglesia, tampoco se consideraba el bautismo una credencial de legitimidad o de mejora de condición humana, dado que si este era un sacramento impuesto y no deseado directamente por el esclavo no podía ser causa suficiente para ser considerado un verdadero cristiano y, en consecuencia, no se erigía como una razón válida para habérsele de otorgar la libertad ${ }^{38}$. La legislación eclesiástica prohibía que un cristiano fuera esclavo, pero esta prohibición no les libró de la esclavitud, aunque pudieran llegar a ser libres más fácilmente que otros ${ }^{39}$.

En Cataluña, donde había muchos siervos cristianos, la esclavitud era muy corriente, aunque teóricamente limitada a los musulmanes y otros extranjeros, prisioneros de guerra griegos o sardos, los primeros considerados como cristianos marginales y los segundos rebeldes, catius de guerra. El argumento de ser hombres o mujeres "de buena guerra" significaba que no procedían de robo, porque en caso de ser así podría restituírseles la libertad y la venta habría sido nula, es decir, se avalaba la legalidad del acto realizado. La esclavitud no estaba contestada ni afectaba a los miembros de la comunidad cristiana ${ }^{40}$. En relación a los esclavos y esclavas, tan numerosos en las

${ }^{35}$ EBNER, "Der Bauer in der mittelalterlichen Historiographie", p. 104.

${ }^{36}$ EIximenis, Dotzè, II, p. 43.

${ }^{37}$ La bibliografía sobre esclavitud es muy amplia, sería excesivo citarla aquí con exhaustividad. Remito la consulta a obras colectivas de singular interés, cfr. Ferrer i Mallol, Mutgé i Vives, De l'esclavitud a la llibertat, 2000; GuILLÉn, Trabelsi, Les esclavages en Méditerranée, 2012; y muy especialmente la penúltima Settimana de Prato, Schiavitù e servaggio, 2013. También a recientes tesis doctorales accesibles on line, y a las citas bibliográficas en ellas contenidas, $c f r$. Marzal Palacios, La esclavitud en Valencia, 2006; Armenteros MARTínez, La esclavitud en Barcelona, 2012.

${ }^{38}$ Sachetti, Sermoni Evangelici, p. 94; Florentinus, Summa Teologica, III, p. 60-61.

${ }^{39}$ La pignoración de la casa de Premiá, en el Maresme, a finales del siglo XIII, me permite constatar que entre los bienes muebles -omnia superlectitia- habían cinco esclavos, tres bautizados y dos sarracenos, Archivo de la Catedral de Barcelona, ACB, 4-93-4.

${ }^{40}$ No será hasta más tarde, con la conquista española del Nuevo Mundo, que la cuestión de los derechos pertenecientes a los no-cristianos fue explorada de forma extensiva, aunque también hubieron anticipaciones 
ciudades medievales ${ }^{41}$, muy pronto se tomaron medidas coercitivas que aumentaron su humillante situación. Así, en la ciudad condal, en 1332, se pregonó un bando de este tenor:

que neguna persona de qualque condició sia no gos albergar de nits negun catiu ne cativa, ne prestar sobre penyora, ne comprar res que catiu o cativa vena, ne acullir-los negunes coses de dies ne de nits, si donchs no feya ab volentat ho amb consentiment de senyer del catiu o de la cativa [...] que neguna persona de qualque condició sia no gos jugar ab negun catiu a negun joch de daus, ne altre joch hon diners ayen ${ }^{42}$.

Si analizamos las ocupaciones a las que se destinaban los esclavos y esclavas se comprueba que, sin duda, se ocupaban de las tareas más pesadas, o aquellas que, por su naturaleza humillante eran rechazadas por los miembros del servicio doméstico. Los hombres, en el medio rural, generalmente labraban los campos o cuidaban del ganado ${ }^{43}$; en la ciudad hacían de mozos en los obradores o, temporalmente, se cedían para limpiar letrinas o recoger carroña echada en las calles. A las mujeres, los deberes asignados correspondían sobre todo a labores domésticas, hilar y tejer para las necesidades del hogar - pero también para terceros en calidad de trabajadoras a domicilio-, coser, acompañar a la ama a comprar ${ }^{44}$, cocinar, trajinar leña, limpiar la casa. Más rentable aún resultaba la esclava que recientemente había parido, así podía lactar los hijos de los amos o ser colocada como nodriza en otras casas privadas o en entidades asistenciales que acogían recién nacidos abandonados ${ }^{45}$. Un ejemplo de la presencia de esclavos en Tarragona nos viene documentada por la descripción de una pelea, en 1383. Resulta que el veguer del rey, mientras hacía de vigía de la ciudad, al atardecer, pasó delante de la casa de Guillem Banastull. Entonces oyó que lastimaban a la esclava de éste. Llamó a la puerta pidiendo que le abrieran, porque estaba cerrada con llave. Puesto que nadie acudía, empezó a darle empujones, hasta conseguir hacer saltar la balda. Entró en la casa y encontró un esclavo, de Bonastull, y le dijo: fill de ca, perquè no m'obries?, pegándole en la cabeza con una daga que llevaba en la mano, hiriéndole ligeramente. Los cónsules consideraron que un acto de este tipo era muy reprobable, e açò sia fort gran perjudici de la ciutat, en consecuencia declararon que enviarían mensajeros al duque y al rey para que el veguer fuera retirado del

en el Medievo, en particular en el derecho canónico. Cfr. Pagden, The fall of Natural Man; Muldoon, Popes, Lawyers and Infidels.

${ }^{41}$ CuAdrada, "Esclaus i esclaves", p. 325-340.

${ }^{42}$ Archivo Histórico de la ciudad de Barcelona, AHCB, Llibre del Consell, I-12, f.10.

${ }^{43}$ Archivio di Stato di Prato, Archivio Datini, ASP, AD, 893, 6.VIII.1409 - es una carta enviada de Menorca a Mallorca-: ... si a vós pleurà, n'e compresets dos sarts e una sarde, qui sien de adat de XX anys fins en XXX, e los hòmens que sàpien de pagecie...; $\mathrm{ASP}, \mathrm{AD}, 893,11 . \mathrm{XII} .1409:$...vos avia ascrit que a mi me avien dit hòmens de sí que n'an comprats que los sarts fineren a XXX o a XXXVf., perquè prech que si per aquest for me podets comprar hu qui s'entenia en bestiar, que.l me comprets...

${ }^{44}$ En 1393 Francesco di Marco Datini manda comprar una schiavetta, y detalla las tareas domésticas que habrá de realizar: e la chagione per ch 'io v'o chostei sie solo per farle lavare l'eschodele e portare su legne e pane al forno, e che fa simile chose, e però vuole essere bene fondate e di buono nerbo, però vorò duri faticha assai... (se ha de pensar que la quiere de ocho a diez años de edad), ASP, AD, 791, 15.V.1393.

${ }^{45}$ Origo, "The domestic enemy", p. 362. 
cargo, e que puys que.s faça inquisició contra ell e que sia perseguit en totes aquelles maneres, axí en protest com en altres guises que fer-se poran ab justicia ${ }^{46}$.

\section{OTREDAD DEL EXTRAÑO}

En tercer lugar se da una alteridad al extranjero ${ }^{47}$, al desconocido, a la desconfianza que genera en especial el forastero por su acento, sus costumbres y sus modos. Los teóricos justificaron entonces la coerción abogando por la consolidación del Estado. En Barcelona, en unas ordenaciones de $1324^{48}$ se dictó que tot mendicant, sia hom sia fembra, que sia estrany ne d'altra llengua, que sia en Barchinona, había de salir del territorio de la ciudad en cuatro días. Si la asistencia y la beneficencia exigía en gran medida el conocimiento y/o control de los asistidos, no nos ha de extrañar la poca disposición de los organismos públicos hacia los foráneos indigentes. Más todavía cuando se trataba de pobres de otras naciones, los cuales recibían un trato aún más peyorativo y discriminativo, según se deduce de las Ordenaciones del Consejo de Ciento barcelonés en la primera mitad del siglo XIV: tot mendicant, sia hom, sia fembra, que sia estrany, ne d'altra llengua, que sia en Barchinona, ha de sortir dels termes de la ciutat abans de quatre dies ${ }^{49}$.

Prevenciones que no son únicamente propias de la capital del Principado, sino que encuentran paralelismos en muchas otras ciudades, las cuales delinean una fuerte política de cerrazón hacia los forasteros. Menos de quince años después del primer impacto de la Peste Negra, en 1362, el obispo de París deploraba la falta de sitio, de noche, para los desgraciados, en hospicios y hospitales ${ }^{50}$. Entonces, en la distribución de ropa o de comida efectuada según un calendario regular por los monasterios y los conventos, las cofradías y los hospitales, las mesas de pobres o las limosnas pías, se veía una riada de hambrientos agolpándose como perros, como sucedió en los funerales del cardenal Pierre de Luxembourg, donde, según Molinet, se juntaron diez mil pobres, muriendo asfixiados treinta y ocho de ellos ${ }^{51}$. En Bolonia se crea, en el 1357, el llamado Ufficio delle bollette ${ }^{52}$, un fichaje sistemático de los indigentes que pasaban por la ciudad de la Emilia-Romagna, con la finalidad de controlar a menesterosos y vagabundos, empezando a ser regulares y normales las medidas de expulsión:

Vi erano preposti prima uno, poi due (1454) ufficiali eletti nei consigli cittadini. Essi esercitavano la sorveglianza sulle prostitute e sui forestieri che entravano ed uscivano dalla città, ricevevano le denunce che osti ed albergatori erano tenuti a pre-

46 Actas, 4, p. 78.

${ }^{47}$ Gual VILÀ, Justícia i terra, p. 331, Armari II, calaix 21, doc. 24: en las cárceles de Poblet está preso Joan Bidet, gascón, bandolero, que iba en cuadrilla con pedreñal con otros que mataron, dañaron y desafiaron. Se resalta que es de nación francesa, (30.09.1571).

48 AHCB, Llibre del Consell, I-8, f. 25.

49 AHCB, Llibre del Consell, I-8, f. 25 (1324).

50 Coyecque, Ernest, L'Hôtel-Dieu de Paris, p. 293.

51 MonteIL, Histoire des Français des divers états. II, p. 14 y ss.

52 Archivio di Stato di Bologna (ASBo), Ufficio delle bollette e delle presentazioni dei forestieri, regg. 29. SimeOni, "L'uficio dei forestieri", p. 71-95. 
sentare circa l'alloggio fornito a forestieri ed avevano altersi l'incarico di tenere a disposizione corrieri per le lettere ed ambasciate del comune.

En tiempos de carestías las medidas se endurecían. Por ejemplo, en 1374, año fatídico de grandísima hambruna y de falta absoluta de subsistencias ${ }^{53}$, en Barcelona se lanzaron bandos continuados para prohibir la entrada de gentes extrañas:

Ara hoiats, per manament del batle ordonaren los consellers e promens de la ciutat que negún patró de nau, leny o altre vaxell strany o privat no gos negunes persones mendicans o pobres, ne sclaus de qualsevol nació sien, ne jueus, portar o fer portar ne descarregar en la ciutat de Barchinona o en lo territori o termes d'aquella o dins la vegeria sua ${ }^{54}$.

Igualmente se decretó que todo pobre saliera de la ciudad si no querría trabajar:

que tot hom e tota fembra qui acapta o vaie acaptant mendicant, dins VIII dies primers vinents se sia mes ab senyor o ab dona per star e guanyar la vianda, o.s sia mes en alcun offici e faça feyna de ses mans, en tal manera que no acapte, o dins les dits VIII dies serà gitat de la ciutat stobat. E si altra vegada hic serà atrobat, serà penjat per lo coll sens tota merce ${ }^{55}$.

Si esto se mandaba en el mes de julio, poco debía mejorar la situación, porque el 26 de noviembre del mismo año se estipulaba que nadie que fuera de nación extranjera habitara en la ciudad ${ }^{56}$. Aunque tampoco esta disposición arregló el problema, ya que el 11 de febrero siguiente se volvió a pregonar otro bando por las calles para que los mendigos marcharan, haciendo constar que

com moltes gents pobres dels prats d'Urgell e d'altres lochs de Cathalunya, e encara d'altres parts stranyes sien vengudes en la ciutat de Barchinona, e jatsia sien adrets de lurs membres molts d'ells vagen mendicant per la dita ciutat, e molts d'aquells hi stan vagabunts, no volents fer alguna faena...

se les dio un plazo de tres días para irse, bajo las mismas penas anteriores ${ }^{57}$.

53 Entonces la puerta de la muralla queda abierta a cualquiera que traiga víveres: que tothom strany, qualsevulle condició sia, qui vulla metre e recollir sí e sos béns dins la ciutat de Tarragona, puxe metre dins aquella, salvament e segura, tots blats, vins e altres vitualles.

54 AHCB, Llibre del Consell, I-24, f.46v.

55 Ibidem. (21-VII-1374).

56 Ibidem, f.49.

57 Ibidem, f.132-132v: Ara hoiats, per manament del veguer e del batle de Barchinona ordonaren los consellers e promens de la ciutat, per squivar perills qui per açòs porien esdevenir o seguir, que alcuna persona de stranya nació, de qualque stament, lig o condició sie, no gos ne presumescha d'estar e habitar de vuy avant en la ciutat de Barchinona, ne en lo suburbi d'aquella per qualsevol rahó, ans encontinent sich haie exir sots pena de mort e encorriment de tots sos béns; e que d'aquí avant an.y puxen tornar ne star si donchs no ha albarà del señor Rey o dels dits consellers, ans tota persona qui hic sàpie hòmens e fembres d'estranya nació los haie decontinent denunciar a dit veguer. E encara, a tot hostaler o hostalera o altre en los alberchs dels quals venguen a posar albergar, los haien a denunciar axí com es dit. En açò, enperò, no són enteses los familiars o domèstichs del senyor Rey ne de la senyora Reyna, ne encara aquells o aquelles qui axí, per rahó 
En Tarragona, en 1369, el consejo municipal dictaminó que sia provehit que tot hom strany que sia mundari e sospitós haja axir fora la çiutat, e que si hic són trobat fins que la ost sia tornada, sia penjat pel coll58; en 1374 se refiere que algunos hombres expulsados de la ciudad, hòmens de mala vida, se encuentran en Constantí, por tanto se decidió ordenar a algunos ciudadanos que tomaran las armas, para que negú estrany dampnifficàs algú de la Ciutat ${ }^{59}$; en 1388 se citó com diverses persones omeyeres [homicidas] les quals han comeses omeys molts e diversos en la ciutat... tantost sien stades tornades e stiguen en la dita ciutat, que se procediera en consecuencia ${ }^{60}$; y en 1400 se ordenó procesar y castigar a los malfaytors que habían cometido alguns ladronices e altres maleficis ${ }^{61}$.

A los expulsados se sumaron los rechazados. Desde la primera mitad del siglo XIV en algunos lugares de Europa a los zíngaros, llamados bohemios o egipcios, según las suposiciones relativas a su origen. Su apariencia física, lengua, nomadismo, hurtos o crímenes que se les imputaban, los colocaron en todo Occidente, muy lejos del margen. Los gitanos aparecieron en la península a mediados del siglo xv, fueron vistos de forma muy parecida a los vagabundos, siendo objetos y sujetos de no pocos altercados y problemas. El 23 de julio de $1577^{62}$, Anna, mujer de Francesc Gavarri, natione bohemiarii, oyó decir a su marido que el baile general había decretado pena para que no volviesen más al señorío, por culpa de una mujer de su compañía se vieron forzados a volver por allí -Vimbodí, cerca de Poblet-, y no porque tuvieran ganas de injuriar al abad. Por este motivo encarcelaron a su marido. Saliendo de Vimbodí hacia Tarrés encontraron un rebaño de ganado y cogieron una borrega para comer y pasar su vida, la tenían desollada cuando el baile se la cogió. Los gitanos huyeron por temor de ser encarcelados; así van declarando otros y otras de la compañía, Paula, María Ángela, Joan Favian, gitanos, y Nicolau de Salvatierra, del reino de Aragón.

El desplazamiento de las gentes del campo hacia las ciudades no significaba el fin de sus miserias. Al contrario, agobiada por su incapacidad técnica, la multitud de pobres siervos sin especialización estaba sujeta a las variaciones de la contratación diaria. En París, a inicios del Cuatrocientos, el 50-60 \% de la mano de obra esperaba en paro cada día, y con suerte conseguía ser remunerada 250 días $/$ año $^{63}$. Los salarios, precarios, provocaron los conflictos de trabajo en Flandes. Su inferioridad a los precios de suministro aleatorio comportó la inseguridad frecuente, deprimió los niveles de vida, en Toulouse, Rouen, Lyon, París o Barcelona. A las anotaciones del burgués anónimo que relata la vida de la capital francesa entre 1410 y 1450 corresponde la amarga observación, en 1419, de un rouenés coetáneo: Ne pensoit chascun fors que de $s o i^{64}$. En Reims, en 1434, se prohíbe a los extranjeros frecuentar los burdeles, lo

de mercaderia, com encara per exercici de lur offici stan e han acustumat star, e tenen lur alberch o domicili en la dita ciutat o suburbi d'aquella, ne encara sclaus ne sclaves, ans aquells franchament hic puxen star e habitar sens encurriment de la dita pena

${ }^{58}$ Actas, 3, p. 19.

${ }^{59}$ Ibidem, 75.

${ }^{60}$ Actas, 7, p. 44.

${ }^{61}$ Actas, 8, p. 89.

${ }^{62}$ GuAl VILÀ, Justícia i terra, p. 359, Armari II, calaix 22, doc. 28.

${ }^{63}$ Geremer, La main d'oeuvre salariée.

${ }^{64}$ Cochon, Chronique normande, p. 347. 
que implica la doble ventaja de controlarlos e impedirles llevar una vida disoluta; en Troyes, cuando el pánico está a punto de instalarse en la ciudad por falta de granos, se expulsa a los mendigos, extranjeros, madamas y a todos aquellos que son gens de petit et mauvaiz gouvernement ${ }^{65}$. En 1448, en Bayeux (Normandía) se acusa al maestro Andrés Brandi, médico español -extranjero, por tanto- de abusor in arte medicina, por poseer libros sospechosos que contenían capítulos con contenidos supersticiosos, libros que fueron quemados públicamente, mientras su propietario se disculpaba afirmando que ignoraba esos detalles ${ }^{66}$.

\section{$* * *$}

Hasta aquí me he referido a tres tipos de otredades, las cuales admiten diversos grados de exclusión y/o marginación. Las diferencias conceptuales de estos términos encuentran un sentido específico en la Baja Edad Media y los inicios de la Modernidad, visibles en los mecanismos de desplazamiento y desprecio. Es evidente que separar unas otredades de otras puede resultar artificial; a pesar de ello es operativo a fin de resaltar las diferencias entre ellas. El Otro, la Otra, es un concepto opuesto a la identidad, a la mismidad, y se refiere a aquello que es "otro" frente a uno/a mismo. Aunque el concepto implica que el Otro sea distinto o diverso, no implica la obligatoriedad de exclusión, así sucede con las mujeres, los niños, los viejos, los campesinos o los esclavos; pero no con los forasteros o los gitanos, mucho más asimilados a sujetos con potencialidades peligrosas. La exclusión social significa la falta de participación de segmentos de la población en la vida social, económica y cultural de sus respectivas sociedades, debido a la carencia de derechos, recursos y capacidades básicas. $\mathrm{La}(\mathrm{s})$ exclusión(es) -disciplinamiento social, reconocimiento visual, eliminación ${ }^{67}$ - conducen a situaciones de pobreza, vulnerabilidad y marginación. La marginación, a su vez, denota una situación social de aislamiento e inferioridad, pero también trasluce la separación o apartamiento de un individuo o colectivo en el trato social -gueto o segregación. Uso en especial esta última acepción para desarrollar mis reflexiones acerca de las y los marginados.

\section{MARGINACIÓN FÍSICA}

La marginación física nos conduce a los contrets -disminuidos, mutilados-, enfer$\operatorname{mos}^{68}$ y $\operatorname{locos}^{69}$. Eiximenis proponía integrar a los minusválidos en la sociedad, obligándoles a hacer alguna tarea útil. Que los ciegos tañeran las campanas o mancharan

${ }^{65}$ Roserot, Le plus ancien registre, p. 12.

66 Neveux, François, "Les marginaux et le clergé”, p. 17-41.

${ }^{67}$ Córdoba de la Llave, cit. nota 4, p. 37.

${ }^{68}$ Sobre enfermedad, $c f r$. GonzÁlez de FAuve, "Medicina y Sociedad", p. 205-211.

${ }^{69}$ Un libro reciente sobre discapacidad -ceguera, sordera, locura, embarazo o edad- en la Edad Media, en Eyler, Disability in the Middle Ages, discapacidad analizada desde las ópticas de la literatura -Leyenda del rey Arturo, Cuentos de Canterbury, sagas nórdicas-y la historia. En relación a los dispositivos municipales para la atención de la enfermedad, $c f r$. PIÑEYRÚA, "Caridad cristiana", p. 61-107. 
fuelles de herreros; que los cojos vendieran en el mercado o enseñaran a leer a los niños, que los mancos hicieran de correos o chafaran cuero... En Barcelona hubo el intento de aislar a estos desfavorecidos en un espacio único de la ciudad, en las casetas construidas en el Portal dels Orbs (ciegos) ${ }^{70}$, diciendo que así se acostumbraba según práctica antigua.

Josep Hernando ha estudiado la evicción de los esclavos en los contratos de compraventa, en su trabajo existen aportaciones notables en cuanto a las deficiencias por patología susceptibles de ser capaces de rescindir el negocio jurídico. Según el Digestum se entendía por enfermedad o morbus el hábito de un cuerpo contra aquello que es natural, es decir, lo que hace su uso menos apto para lo que la naturaleza le dotó, la salud. Podía afectar a todo el cuerpo, como la tisis y la fiebre, o bien sólo a una parte, como la ceguera. Por vicio o vitium se concebía un defecto, como la tartamudez. De todas formas, para evitar dudas, se unió enfermedad/morbus y vicio/vitium como si fueran sinónimos, y así lo encontramos en la Edad Media. Según el Derecho Romano los vicios o enfermedades objeto de devolución de los esclavos por venta fraudulenta o engañosa eran únicamente las enfermedades del cuerpo, no las del espíritu. Eran enfermos de espíritu los fanáticos -fanatici-, furiosos -furiosi, enloquecidos como bacantes - circa fana bacchatus-, tímidos -timidi-, codiciosos-cupidi-, avaros -avari-, iracundos -iracundi-, melancólicos -melancolici-, soberbios -protervi-, jugadores o ludópatas -aleatores-, bebedores -vinarii-, glotones - gulosi-, impostores o mentirosos -impostores aut mendaces-. Pero eran objeto de disputa por la incertidumbre de su origen, de si venía del cuerpo o del ánimo la enfermedad mental o la discapacidad, los efectos de la cual eran la incoherencia en el habla o la falta de comprensión, de lógica o imposibilidad de aprendizaje, la necedad o la estupidez. Como lo eran también muchos vicios o enfermedades del cuerpo, jorobados y encorvados; sarnosos, sordos, los que tenían callosidades en los pies -impetiginosi-; los castrados-spandones-, si les faltaba un testículo; el tartamudo, patizambo; al que le faltaban dientes, o tenía un solo ojo, tumores en el cuello u orzuelo, el zurdo, el que sufría halitosis; las preñadas, las que acababan de parir, las estériles; los que les faltaba la campanilla. También podían ser objeto de devolución los esclavos sin lengua, los mudos, si les faltaba un dedo del pie o de la mano, o un miembro, los miopes, los nictálopes, los que tuvieran un pólipo, o un clavo en el pie, los cojos, la esclava que paría una criatura muerta, la que tenía los menstruos fuera de tiempo, los que tenían enuresis o incontinencia urinaria ${ }^{71}$. Todo este listado nos ilustra sobre la concepción de la enfermedad no epidémica en la época que, como vemos, es amplia y extremadamente variada.

El 5 de mayo de $1433^{72}$ el Consejo de la Ciudad de Barcelona, a fin de evitar los litigios y para que todos supieran a qué atenerse en los contratos de compraventa de esclavos, en los que el vendedor se obligaba a la evicción y a los vicios y enfermedades según uso y costumbre de Barcelona, se emitía una ordenanza que decía:

${ }^{70}$ Archivo de la Corona de Aragón, ACA, Reg. 2.158, fol. 3: cum predictis qui claudos et cecos et alias infirmitates fetidas habentes, hospitant iam sit consignatus pro habitacione vicus nuncupatus vulgariter 'Dels Orbs', extra menia nova civitatis iamdicte, in quo vico ex usu antiquo sunt soliti insimul melius habitare.

${ }^{71}$ Hernando, "L'estat físic dels esclaus", p. 417-418.

72 Ibidem, p. 424-425. 
... vendrà lo dit sclau o sclava per bo e sa, sie tengut e obligat al comprador de aquells per les malalties o infirmitats següents, ço és:

En passions de cap: de mania o oradura, epilèpcia o mal de caure.

En passions de pit: de mochayca, passió o scupiment de sanch, e de azma.

En passions de corde: cardiacha, tremor de cor.

En los renyons o vexiga: de mal de pedra, urinar sanch, morenes, urinar en lo lit.

En la mara: de exir lo coll de la mara.

E si les mèstrues cessen en lo temps covinent, ço és, de XVI anys tro a XXXXV anys, e de sobrehabundància de mèstrues.

En les juntures: de artèticha, passió ciàtica, puagra, çiragra, e d'altres dolors de junctures en altres membres vinents.

Sin embargo, la enfermedad más temida y, por tanto, apartada desde la alta edad media, era la lepra, para las demás enfermedades existía mayor tolerancia, no producían el mismo temor, eran algo habitual y cotidiano, por lo menos antes de la llegada de la peste apocalíptica. Los conocimientos médicos relativos a la lepra provenían de la teoría de los humores, de un exceso de bilis negra, se decía. El doliente de ojos prominentes, nariz apretada, cara pálida, con infecciones de la piel, úlceras o alopecia, era decretado leproso por uno o varios médicos, a veces con la ayuda (cada vez con menor intensidad al final de la edad media) de un tribunal formado por enfermos. La lepra era percibida por la medicina medieval desde una doble óptica: por un lado como una enfermedad venérea y, por el otro, como una manifestación de decadencia moral. En el siglo XIII ya había en Francia más de dos mil leprosaria, en Inglaterra y Escocia unos 220 para una población de un millón y medio de personas ${ }^{73}$, es obvio que las leproserías, por ser una enfermedad considerada contagiosa, se ubicaban fuera de las ciudades. Los hospitales de los mesells alejan pues, a los enfermos ya en el s. XII, momento en que el aumento del contagio es paralelo al desarrollo urbano; las ciudades abiertas a los intercambios eran terreno privilegiado de la endemia leprosa. La interpretación de la lepra como castigo divino y enfermedad muy grave es evidente en Eiximenis, cuando refiere la persecución del emperador Constantino contra los cristianos y la subsecuente sanción de Dios: per lo qual peccat plach a Déu plagar lo dit Constastí de malaltia greu e fort gran qui s'appellava lebrosia, a la qual malaltia a guarir negun hom mortal per neguna sciència, ne art, ne medecina, no podía dar consell ${ }^{74}$. Se comprueba también el cambio de actitud que se produce desde el comienzo del Trescientos hacia los enfermos. De esta época proviene el asunto de la acusación de envenenamiento de los pozos, tema recurrente, vinculado a los pastoureaux, los judíos y los leprosos, dentro de una tendencia muy fuerte hacia el rechazo radical que se inscribe en el contexto de las crisis que conoce el fin del medievo ${ }^{75}$. La pérdida de derechos de los leprosos se convierte por otra parte en total en el siglo XV, cuando se instauran los ritos funerarios - misa seguida de una procesión, simulacro de inhumación, canto del Libera me- para hacer pasar los enfermos del mundo civil al mundo de la clausura forzada: la leprosería se transforma en la antesala de la muerte.

${ }^{73}$ Cover, "People with leprosy", p. 317.

74 EIXIMENIS, Francesc, Libre apellat, cap. 75.

75 Cuadrada, El llibre de la pesta, p. 13-20. 
Estos espectáculos revelan el gusto creciente hacia lo mórbido, pero desvelan igualmente la exasperación de la exclusión ${ }^{76}$.

\section{MARGINACIÓN ECONÓMICA}

Se daba también una marginación económica. La pobreza ${ }^{77}$ separa, aísla los poderosos de quienes nada tienen; en este caso, de todas formas, el rechazo no era total, no a todos los pobres, los pobres vergonzantes continuaban viviendo en barrios de la ciudad mezclados con otras gentes, hecho que a duras penas sería extrapolable a mendigos y a vagabundos. En el capítulo 873 del Dotzè del Crestià Eiximenis ${ }^{78}$ distinguía entre la pobreza de grat y la pobreza per força; la primera, elegida por gusto, como la de sí mismo y la de sus compañeros legos, era respetada por ser considerada el missatge evangèlic que hom intenta seguir ${ }^{79}$. La segunda, en cambio, la forzada, era la major miseria qui al món sia, la que el franciscano entendía como contrapunto a la riqueza, la que permitía al rico, si daba limosna, conseguir la vida eterna: les riqueses són dades perquè.n salven lurs ànimes. Existe, pues, una ambivalencia en las actitudes respecto a los pobres, un comportamiento que combina y distribuye el desprecio y la piedad, una contradicción entre el ethos medieval de la pobreza y la realidad social. Un punto de inflexión evidente respecto al cambio de mentalidad viene del tremendo impacto de la Peste. No es casualidad que la primera gran etapa de represión del vagabundeo se afirme en Francia a partir de la ordenanza de 1351. Eco de ello es la denuncia de Eiximenis de la vida ociosa de algunos pobres, recomendando que los verdaderos llevaran un señal de plomo para poder ser fácilmente identificados, sugerencia recogida por los jurados de Valencia en los estatutos de $1395^{80}$. Las leyes de pobres ${ }^{81}$ nacieron de las necesidades tanto asistenciales como represivas, confundiendo entonces a mendigos y mendicantes con ociosos y maleantes, haciendo posible un profundo cambio ideológico en la percepción del trabajo y del pauperismo ${ }^{82}$. Existió, como bien expone Rafael Narbona ${ }^{83}$, una correlación entre la persecución de indeseables con la creación y generalización de políticas ciudadanas reguladoras del trabajo, paralelas a las políticas asistenciales y hospitalarias ${ }^{84}$ puestas en vigor con creciente interés por los poderes urbanos.

${ }^{76}$ BÉRIAC, Histoire des lépreux, p. 160-162.

77 López Alonso, La pobreza en la España medieval, 1986, para una visión general. He profundizado en el tema analizándolo desde una perspectiva de más larga duración, $c f r$. CUADRADA, "La pobreza en Cataluña (ss. XIII-XV)", en prensa.

${ }^{78}$ EIximenis, Dotzè, II, p. 469-471.

79 Martínez, Micó, "Els pobres a la literatura", p. 32.

${ }^{80}$ Ivars, El escritor Fr. Francisco Eximénez, p. 229.

${ }^{81}$ Narbona Vizcaíno, "Las leyes", p. 165-284.

${ }^{82}$ Cherubini, "I lavoratori fiorentini”, p. 101-112; GeremeK, Le salariat dans l'artisanat parisien, p. 101102.

${ }^{83}$ Narbona Vizcaíno, "Las leyes", p. 174.

${ }^{84}$ Gallent Marco, "La asistencia sanitaria", p. 135-164; Cuadrada, El llibre de la pesta, p. 169-183; Martínez García, Luis, "Pobres, pobreza y asistencia" p. 67-108; Escobar CAMacho, "La pobreza: de virtud a vicio" p. 109-144. 
Así, la crisis de la sociedad rural y las transformaciones que trastornaron las relaciones de producción provocaron que caminos y campos fueran cada vez más poblados por vagabundos, bribones y publici et famosi latrones ${ }^{85}$. Los estudios realizados en Italia muestran que no se puede hablar todavía, en la baja medievalidad, de verdaderos fenómenos de violencia organizada ni de revueltas a gran escala, de bandidismo social. Para la Toscana, distinguiendo entre bandos políticos y bandidaje, se ha subrayado la existencia de una micro-conflictividad endémica, la presencia de bandoleros en el campo, con un radio de acción muy local dentro del cual los latrones et vagabundi eran perfectamente conocidos por sus comunidades de pertenencia, lo que confirmaba el fundamento de las advertencias de los oficiales que denunciaban la complicidad tácita de las poblaciones rurales y las amenazaban, al considerarlas responsables colectivas de los $\operatorname{robos}^{86}$. La pobreza aparecía con una imagen nueva, ahora masiva y forastera, lo que dio lugar a que se hubiera de conjugar la caridad y la asistencia con el castigo y la represión, en el proceso de construcción del estado, en el que jugaron los lenguajes políticos, los valores identitarios ${ }^{87} \mathrm{y}$ los proyectos de gobierno. Un nuevo encuadramiento mental e institucional que tendía, pues, a frenar la espontaneidad del don, efecto de la evolución del pensamiento económico cristiano y su incidencia social en la definición de un ideal cívico y en la articulación de la vida urbana que ello comporta ${ }^{88}$. La casuística de la limosna replica a la casuística de la usura. La intervención de los poderes públicos canaliza y reglamenta la beneficencia, la limosna evoluciona del regalo a la entrada contable. Lentamente, hacia finales del siglo XIV, nace esta idea de la superioridad moral del préstamo sin interés, porque alienta y estimula el trabajo; según la cual la mendicidad es contraria al provecho común y a la noción humanista de la dignidad de la persona. La generación de Giovanni Dominici y de Antonin de Firenze es también de la san Bernardino de Feltre. Estamos en los inicios de los Montes de Piedad.

En las ciudades, como sucede en el París bajomedieval ${ }^{89}$, la criminalidad era una actividad cotidiana, María Asenjo la titula, junto a la violencia, un pecado urbano ${ }^{90}$. Contra ella se organizó la policía ciudadana, la legislación contra el vagabundeo, el robo y el crimen. Se trataba de una ciudad, como tantas otras coetáneas, donde los ricos y los pobres se rozaban, las movilidades urbanas eran constantes y donde los islotes de pobreza eran además puntos de concentración natural de los indigentes, reinos exclusivos de los miserables. Urbes con tremendas dificultades de abastecimiento, acentuadas por la especulación de los recursos alimentarios, la desigual gestión de la distribución y las tensiones sociales ${ }^{91}$. Pero no todo proviene de los nihil habentes. Otros que desde el punto de vista económico no están todavía fuera de los márgenes,

85 Dean, Crime in Medieval Europe; Cherubini, “Appunti sul brigantaggio” I, p. 103-133.

${ }^{86}$ PINTO, "Un vagabondo, ladro e truffatore" V, p. 327-345; CADUfF, "I “publici latrones"”, XVIII, p. 514516.

87 Evangelisti, La costruzione di uno stato, p. 29-52.

${ }^{8}$ En lo relativo a la economía de la caridad, GAZZINI, Studi confraternali, 2009; LooIJESTEIJN, "Funding and funding private charities", p. 199-239; y también la reciente Settimana di Studi de Prato, Assistenza e Solidarietà in Europa, 2013.

${ }^{89}$ Geremer, Les marginaux parisiens; Mitre Fernández, Ciudades medievales europeas, p. 176-188.

90 Asenjo González, "Integración y exclusión”, p. 185- 207.

91 SAlrach, La fam al món, p. 151-156. 
pero que se encuentran en los estadios más ínfimos de la escala social, como los ciom$p i^{92}$, se rebelan en masa. El 20 de julio de 1378, en Florencia empieza la insurrección de estos despreciados, que pronto reúnen unos 10.000 participantes en una ciudad de 55.000 habitantes después de la hecatombe provocada por la epidemia. Durante cuarenta días imponen su participación en el gobierno florentino, luego el orden será rápidamente restablecido por los magnates, el Arte di Calimala, y una represión sin piedad barre todo resto de tumulto, dejando marcas indelebles en la conciencia de los apagados trabajadores.

Las representaciones colectivas traducen un hecho real, el flujo hacia las ciudades, desde finales del siglo Xv, de un número creciente de gentes rurales desarraigadas. El modelo propuesto por Bronislaw Geremek ${ }^{93}$ se traduce en ley verificada en el conjunto de Europa. El pauperismo hunde sus raíces en una desagregación profunda de las sociedades rurales, y los ejemplos franceses, italianos, holandeses o españoles cuentan el mismo hecho: el aumento considerable del porcentaje de familias pobres en los campos, reducidas a la mendicidad. La desintegración de la propiedad campesina y la resistencia, a veces agresiva, de la estructura señorial, están, sin duda, en los orígenes de ese estallido de las células tradicionales. Pero, si la pobreza nace en el medio rural, se transporta rápidamente a las urbes; en tiempos de crisis, se confía ingenuamente en los graneros urbanos, en tiempos normales se espera encontrar trabajo. La inflexibilidad de las estructuras artesanales no permite la absorción de este flujo de mano de obra, y la presión sobre los salarios es tal que vivir de la caridad sin hacer nada es una tentación para quien mal vive trabajando. El peso de los pobres crece entre los siglos XIV y XVI. Los estudios realizados sobre las entradas de enfermos en los hospitales confirman la tendencia que empuja a los desheredados hacia la ciudad.

El modelo de la circulación de la limosna, magnificado por el discurso religioso conservaba un cierto número de comportamientos encontrados: desprecio por el inferior, prueba ante la muestra del mérito a recibir el mendigo, mantenimiento de cada cual en su sitio. No ocurría ni siempre ni enseguida, y entre los dos -el que daba, el que recibía- se instauraba un juego que permitía evitar la simpatía total con el enfermo o el pobre despreciable. El modelo tomó consistencia en la segunda mitad del siglo XII, en el momento en que la multiplicación de los mendigos y los esfuerzos realizados para responder a ello se acompañaron de una exigencia mayor de interioridad; es necesario ponerlo en paralelo a lo que se llamó la "revolución de la caridad ${ }^{94 ", ~ l a ~}$ cual constituye la cara inversa, su sombra. Un modelo tal que se desarrolló después de 1350 y no se modificó verdaderamente hasta el siglo xvI, momento en que la lucha contra la limosna manual y la desacralización del mendigo disminuyó la imbricación de la piedad y del escarnio, y la tensión que había sostenido el juego medieval de la limosna. Lo que el individuo había hecho con la burla - poner a distancia la miseria-

92 Stella, La révolte des Ciompi, p. 61. Explica que la palabra ciompo es un insulto con fuerte connotación social, una expresión del desprecio de los contemporáneos a los que faisaient les tâches les plus sales et répugnantes $[. .$.$] les derniers de l'échelle sociale. Mi elipsis.$

93 GeremeK, "La popolazione marginale", p. 623-640.

94 Que Vauchez fecha de 1130 a 1260. Cfr. VAuchez, "Assistance et charité”, p. 152. Es la misma época en la que se desarrollará la caridad "individual". 
la sociedad lo hizo después mediante la exclusión, el trabajo forzado y más tarde con el encarcelamiento.

El cambio de mentalidad se da de forma triple: muta la visión que se tiene del pobre, la nueva sensibilidad hacia la miseria, igual que la puesta en marcha de un sistema secularizado de asistencia (las Limosnas Generales, Aumône Générale), en el París en 1530, pero también en la Inglaterra puritana o la España católica; desborda las voluntades de la ética reformada. En efecto, a principios del siglo XVI, se extiende en los medios impregnados de humanismo una actitud de rechazo a la mendicidad, en la que concurren varios elementos. La preocupación por una mejor salubridad urbana, girada hacia los marginados, vectores de peste, se mezcla a un temor social al motín al cual se lanzan los que nada tienen que perder, y más profundamente al corte establecido entre la conciencia humanista y la subcultura imaginada de mendigos y gentes de mal vivir ${ }^{95}$. Dos signos defienden esta hipótesis. La mentalidad que, aunque cultive lo pintoresco, no hace más que aumentar la distancia entre un mundo civilizado y esta sociedad inversa, imaginaria o real, que posee su jerarquía, sus reglas, su idioma. Segundo signo: las marcas distintivas que los reformadores imponen a los asistidos en las limosnas: las bulas o señales de plomo certifican que la diferencia está en proceso de total exclusión.

\section{MARGINACIÓN RELIGIOSA}

Existe asimismo una marginación religiosa o ideológica ${ }^{96}$, no cristianos en general: herejes $^{97}$, musulmanes, judíos, estos últimos, desde un momento dado, encerrados en morerías y juderías, que negun batiat [bautizado] qui sia estat juheu no gos entrar en lo cayl juych, ne a casa de juheu, de dia ne de nit ${ }^{98}$, que algunos han considerado -erróneamente- una marginación étnica. Digo erróneamente, puesto que si lo hubiese sido se me hacen bastante incomprensibles las medidas tomadas para distinguirlos,

95 Gual Vilà, Justícia i terra, p. 605-606, Armari II, calaix 29, doc. 11. Los pahers y el Consejo General de la ciudad de Lérida toman medidas por los robos, homicidios y otros delitos cometidos en la ciudad y territorio, en pueblos vecinos, para perseguir ladrones, bandoleros, asesinos, homicidas y otros malos hombres que han cometido estos delitos y que cada día cometen (29.07.1605).

${ }^{6}$ Voy a centrar mi discurso en los judíos, más algunas referencias a musulmanes, reflejando las noticias de archivo recogidas. Sabido es que las leyes discriminatorias y segregacionistas relativos a judíos y mudéjares, en Castilla, fueron promulgadas en el Ordenamiento de Valladolid de 1412 y confirmadas en la Sentencia Arbitral de Medina del Campo de 1465: reclusión en barrios apartados, prohibición de practicar ciertos oficios, obligación de llevar señales, veto del uso de vestidos ricos, tener criados cristianos, comprar propiedades territoriales por un precio mayor a los 30.000 maravedíes, ejercer todo cargo público que conllevase jurisdicción sobre los cristianos, limitación de los intereses en los préstamos. Para una bibliografía actualizada hasta 2004 vid. Montes Romero-CAmacho, "Judíos y mudéjares”, p. 241-274; Castaño González, "Las aljamas judías de Castilla”, p. 181-203. En relación al “otro” islámico Mitre, “Otras religiones ¿otras herejías?”, p. 9-45; se ha cuestionado también que los mudéjares puedan considerarse un grupo marginado, $c f r$. ECHEVARRÍA ARSUAGA, “Los mudéjares: ¿minoría, marginados o ‘grupos culturales privilegiados’?”, p. 45-65.

97 Sobre herejes y herejías es indispensable la cita a Emilio Mitre, incluyo obviamente sólo últimas publicaciones, además del artículo de la nota anterior, $c f r$. "El enclave hereje", p. 225-244; "Sobre la difícil delimitación de un campo" p. 655-668; "Al margen del valdismo y del catarismo", p. 181-203; "Los pecados desde la herejía”, p. 281-296; Iglesia, herejía y vida, 2007.

98 AHCB, Llibre del Consell, I-12, f. 20v (1332). 
del todo innecesarias si visualmente cualquiera hubiera captado su diferencia sin ayuda de señales ad hoc. Esta exclusión no siempre se efectuó por igual, sobre todo en cuanto a los judíos - echados de Inglaterra en 1290; primer decreto de expulsión en $1249^{99}$ en Francia, quemados en el sur francés en $1320^{100}$, definitivamente desterrados en 1384-, pero bastante tolerados ${ }^{101}$ antes de la crisis del siglo XIV, en la Corona de Aragón. Aunque ya al inicio del Trescientos, en $1302^{102}$, el consejo barcelonés impone distintivos de diferenciación y/o de humillación, así como demostraciones públicas de sumisión:

que tot jueu se deia amagar o agenollar tota vegada que encontre alcú prevere qui vaia combregar o.n venga [...] e negun hom ne neguna fembra no contrast als jueus, que no.s puguen amagar per la rahó damunt dita en son alberch o son obrador [...] que tot jueu deia portar per vila capa vestida de nit e de dia [...] exceptat jueu pobre qui deia portar vestit caperó groch sens capa.

Como vemos, una marginación mediante la subordinación. Aquí se suman dos discriminaciones: la de ser judío y la de ser pobre, con distinciones no iguales para uno u otro ${ }^{103}$. Veinte años más tarde se dictamina que

tot jueu, strany o privat, de qualque condició sia, qui capa juyca no vesta, sia tengut de portar una roda de drap groch cusida sobre la vestadura subirana de la part devant endret dels pits, la qual roda haia un bon pam d'ample de tou de cana de Barchinona, e que.l cercle de la roda haia d'ample I dit de lonch, per tal que tot hom conega que és jueu ${ }^{104}$.

${ }^{99}$ En 1306 ya existía la aljama en Barcelona, Jaime II accedió a acoger sexaginta iudeos et uxoris et infans eorum, cum omnibus bonis et rebus suis, emigrados de Francia, los cuales habían de ser alojados en el call, ACA, Reg. 203, f. 189v.

100 El movimiento de los Pastoureaux, masas campesinas asoladas por el hambre y las epidemias, enloquecidas por una ira sorda y delirante, se dice que exterminó a 140 comunidades judías. Rodney Hilton señaló que los "pastores" constituían por lo general el grupo juvenil y de mayor movilidad entre la población rural, cfr. HiLton, Rodney, Bond Men Made Free, p.100.

101 Las relaciones de tolerancia fueron modificadas por un cambio de coyuntura, a partir del siglo XII, explicó Josep Hernando: "al precisarse el concepto de Christianitas -lucha de las investiduras y progresivo afianzamiento del ideal teocrático, cruzadas y concreción de la Guerra Santa-, se produjo un cambio radical en la actitud de los cristianos hacia todos los órdenes, terrenos y políticos. La condición del pueblo judío sufrió un cambio profundo: se pasó de una economía limitada a una condición de absoluta sujeción e inferioridad frente a los cristianos. Si bien es cierto que no en todos los Estados las nuevas condiciones se impusieron al pueblo hebreo con el mismo rigor, también lo es que, a finales del siglo XIV, la posición de los judíos en todos los Estados europeos se hizo insostenible." Cfr. Hernando, "Tractatus Adversus Iudaeos", p. 10. Sobre la convivencia o tolerancia entre "las tres culturas", $c f r$ r. GARCíA FITz, "Las minorias religiosas y la tolerancia", p. 13-56; Hinojosa Montalvo, "Los judíos en la España medieval” p. 25-41; Blasco Martínez, "Los judíos y su expulsión”, p. 329-338; ídem, "Razones y consecuencias de una decisión controvertida”, p. 9-36.

102 AHCB, Llibre del Consell, I-1, f. 93v. Mis elipsis. Córdoba DE LA Llave, "Los caminos de la exclusión", p. 38, habla de las "marcas infamantes".

103 En las minorías discriminadas se daban también marginalidades internas, una es la pobreza, como vemos. Otras serían los leprosos, locos y discapacitados judíos, cfr. Shoham-Steiner, On the Margins, 2014.

104 AHCB, Llibre del Consell, I-7, 24v. 
Mientras tot sarray de quelque condició sia deie portar los cabells sarcenats o tolts en redó, prop de la oreyla, per tal que tot hom conega que és sarray ${ }^{105}$. Decía Eiximenis:

Que negun crestià no edefic mesquita a moros, ne sinagoga a jueus, ne temple a idòlatres, ne permeta en alt lloc pujar llurs alfaquins, o altres, per lloar o exalçar lo nom de llurs déus estranys o de llurs querimònies, e, en especial d'aquell traïdor celerat, fill del diable e enganador del món, apellat Mafumet de Meca. E fant lo contrari o permetent, si crestià és, sàpia que la sua casa no durarà llongament, ne haurà successió llonga, e la sua ànima serà condemnada per Déu a grans turments per l'assenyalada irreverència que li es feta per aquells crestians qui açò permeten ${ }^{106}$.

Desde la literatura de la época, por tanto, la actitud de censura y desprecio hacia las minorías religiosas es considerable.

En 1322 documento prohibiciones de tirar piedras a los judíos ${ }^{107}$, en especial el día de viernes santo. Sobre ellos vemos repetidos los mismos vituperios y tópicos, suficientemente conocidos, de usureros o de haber sido los causantes de la muerte de Jesucristo. Es por este motivo que se les impone la rueda, que no es otra cosa que un círculo con una cruz en su interior, que significa una $\mathrm{O}$ de occisor -asesino- de Cristo -la cruz-. De color amarillo siempre, color maldito ${ }^{108}$, relacionado con la infamia, que recuerda al otoño y por lo tanto la decadencia o la enfermedad; que pasa a convertirse en símbolo de la traición, la herejía, la mentira, la avaricia, la locura, el engaño, que augura la muerte, tinte de la bilis, del odio, del azufre que adorna el infierno. Ramon Llull llega a considerar que la causa por la cual los judíos no se convierten es porque una vez cristianizados tendrían que abandonar la práctica de la usura. El antisemitismo es, entonces, una salida a la mala conciencia de los cristianos en el momento en que ellos mismos empiezan a mezclarse en el tráfico del dinero, desplazando gradualmente a los judíos de la economía monetaria y comercial ${ }^{109}$. Como bien indica Enrique Cantera, el nuevo poder del dinero fue causa de una alteración substancial en los modos de actuación económicos e, incluso, en las relaciones sociales tradicionales ${ }^{110}$. Eiximenis, san Vicente Ferrer, el Tirant, y muchos más textos coetáneos, reflejan la visión negativa del judío con tanta abundancia de referencias como carencia de originalidad ${ }^{111}$. Habríamos también de preguntarnos por qué existe esta animadversión hacia el pueblo de Israel, mucho más acusada que con los musulmanes. La respuesta es simple. A pesar de ser tratados con los mismos tipos de

${ }^{105}$ Ibidem, f.25.

${ }^{106}$ Eiximenis, Dotzè, II, p. 372.

${ }^{107}$ Ibidem, f.25v.

${ }^{108}$ SAS van Damme, "El Amarillo en la Baja Edad Media", p. 249.

109 Little, Religious Poverty and the Profit Economy, p. 42-57. Sobre las relaciones entre la actividad económica de los judíos y el rechazo social, $c f r$. Hinojosa Montalvo, "Propiedad y nivel de riqueza", p. 677686; ídem, "Las comunidades judías valencianas", p. 80-104; Blasco Martínez, "Los judíos del Reino de Aragón”, p. 121-158.

${ }^{110}$ Cantera Montenegro, Enrique, "La imagen del judío como prototipo del mal en la Edad Media", p. 297- 326 .

${ }^{111}$ Así aparece tambén en el arte ya en el siglo XIII, con una preocupación nueva sobre la apariencia de los judíos, cfr. KRIEgel, Les juifs à la fin du Moyen Age, p. 55 y 251. 
segregación -la territorial, la visual- los primeros detentaban todavía un cierto poder político, más todavía económico y cultural; los segundos, en cambio, en grandes zonas de los reinos hispánicos, no eran nada más que gente residual y vencida.

En las ciudades pequeñas, como Tarragona en los siglos XIV y xV, pocos son los datos que encontramos de musulmanes; en 1378 se tiene noticia que Maymó Romeu, mercader y ciudadano, propone y suplica al consejo municipal que haga justicia en contra de un esclavo moro que había degollado a su esclavo, de nombre Joan $^{112}$, lo cual nos sugiere la posibilidad de la probable existencia de otras personas del mismo origen en igual condición de esclavitud, a pesar de no haberlas documentado. De todas maneras, la presencia islámica se sentía fuertemente, sobre todo en negativo. Es decir, a la contraria, no por los esclavos y esclavas en ciudad, sino por los que habían sido o podían ser capturados por razias musulmanas. En este sentido, como tantos otros pueblos, villas y ciudades de la costa, no falta nunca en las iglesias el bacín de los cautivos ${ }^{113}$ : fue determinado por la mayor parte del Consejo, mediante súplica hecha a propósito, que se averiguaran y se examinaran las cuentas del bacín de los cautivos de la ciudad, y que se recuperaran las cantidades debidas para rescatar dos habitantes, el hijo de na Gotarda, cautivo en poder de los paganos, y un pescador ${ }^{114}$. Y también, en 1387, se hace constar que el honrado comendador del monasterio de san Antonio hage demanat a la ciutat adjuditori [...] com en reembre alscuns catius de la dita ciutat preses en poder de moros, és determinat e tremès als cònsols que provesquen a lur coneguda en reembre los dits catius del bací acustumat ${ }^{115}$.

En relación a los judíos, el municipio tarraconense no sigue el talante general de otras ciudades catalanas o peninsulares. Creo que también este hecho es debido a la escasa relevancia económica de que gozaba la ciudad a finales del Trescientos, hecho que ponen de relieve actuaciones que contrastan con las de otros lugares en relación a los mecanismos de exclusión. Las informaciones que tenemos son exiguas y dispersas, pero no carentes de interés. Por lo pronto, los médicos. En el año 1384 encuentro a mestre Perfeyt Cap, juheu, a quien la jerarquía ciudadana concede por sus trabajos diez libras barcelonesas ${ }^{116}$, donativo que se eleva a siete florines de oro un año más tarde ${ }^{117}$; en verdad el municipio debió de estar bastante satisfecho de sus servicios cuando, tres años después, consta que cobraba ya diez florines ${ }^{118}$. Bien, una actuación de este tipo no tiene nada de particular si se observa desde nuestra perspectiva actual. Al fin y al cabo, si un especialista trabaja a satisfacción de la comunidad, ¿qué hay de extraño que se le remunere en consecuencia? Sí, es verdad, pero no entonces, cuando el antisemitismo era más que palpable en

112 Actas, 4, p. 22.

113 El bacín de los cautivos sólo lo documento en ciudades y pueblos costeros. El que no falta nunca y se encuentra tanto en zonas marítimas como de interior es el bacín (o candela) de los pobres, algunas veces citado como de los pobres vergonzantes.

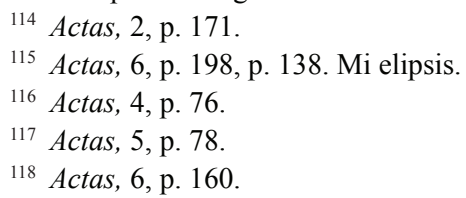


las principales ciudades. En palabras de Eiximenis: que crestians si són malalts no deuen apellar jueus metges, ne d'ells reebre medicines...

En Tarragona habitaban judíos, ejemplo es la disposición de 1386: és declarat per lo dit honrat consell que per neguna raó que neguna juya no sia corredora, no gos usar de offici de corredoria en la dita ciutat ${ }^{119}$. Lo que nos indica claramente una medida proteccionista por parte del grupo municipal, a los mercaderes cristianos y a sus representantes, y, además, al dirigirse a las mujeres judías vetándolas, todavía es más interesante el mandato, dado que demuestra que las judías tarraconenses ejercían la correduría. En la misma fecha el poder ciudadano dictamina ayudar a Abraham Çavillano, sillero y habitante de la ciudad, otorgándole cuatro florines de oro para que pueda pagar el alquiler de su albergue ${ }^{120}$. Esta acción, a mi entender, es, de nuevo, muy ilustrativa. Resulta una evidencia que la ciudad acogiera a los individuos que le resultaban beneficiosos, médicos, comerciantes, artesanos, los y las que tenían capacidad de incentivar mejor vida y aportar riqueza al bien común. Abraham seguramente procedía de Sevilla, desde donde podría haber emigrado antes de las proclamas incendiarias y fanáticas que fray Heredia lanzó sobre la ciudad, convirtiéndola en un baño de sangre judía, luego mancha de aceite que extendería el odio fanático contra los hebreos por toda la península. Tenía consigo sólo un salvoconducto: su oficio. Lo que es impactante, aunque no deja de tener cierta lógica, es la subvención concedida por el municipio. Se me podrá objetar que aún faltaban cinco años para el fatídico 1391, año de los pogromos generalizados, y cierto es que Abraham pedía acogida entonces. Eran años de acusaciones contra los judíos generalizadas: de propagación de la peste por envenenamiento de los pozos, misas negras, sacrificios de niños cristianos. Nótese que algunas imputaciones cambian según el lugar, los responsables de las muertes rituales son los judíos en España y en el Imperio, en cambio los mendigos en Francia ${ }^{121}$.

Pero en Tarragona no es este el único hecho poco corriente.

En 1393 -y esto ya empieza a romper los esquemas- el Consejo de la ciudad acuerda tratar con familias judías que manifestaron su intención en instalarse en ella:

A la proposició en lo dit Consell feta per rahó d'alguns casats de juheus qui.s diu que se'n volen venir star en la ciutat de Terragona e fer call aquí, és determenat que.l fet sia comenat als honrats cònsols [...] donant-los poder de tractar e finar ab los dits juheus per aquella manera que.ls serà vist fahedor.

Este hecho, que parece un contrasentido a causa de los aires de rechazo del momento, tiene una explicación no inmediata pero sí coherente con lo expuesto antes: el poder urbano era consciente de que la comunidad judía era capaz de aportar beneficios económicos, por eso era tratada con tal deferencia. También es creíble que familias fugitivas de otros lugares buscasen una ciudad marítima para poder continuar desde allí con sus negocios comerciales. Y no era sólo el Consejo tarraconense quien

119 Ibidem, 48.

120 Actas, 6, p. 56.

${ }^{121}$ Quaglioni, Esposito, "I processi contro gli ebrei di Trento", p. 282-306; DelumEau, La peur en Occident, p. 378-380. 
conocía su valor mercantil, sino que la misma monarquía, la que invirtió en medidas de consideración para que no desapareciera la judería mallorquina y, con ella, el floreciente comercio con el norte de África ${ }^{122}$. No sabemos si la idea de establecerse en Tarragona prosperó, pero aun así la iniciativa es digna de remarcar. Sea como fuere, está documentado que a partir de los inicios de estos años se puede hablar ya de decadencia de la aljama tarraconense, siendo el espacio destinado a los judíos progresivamente ocupado por cristianos.

Así, el ocaso de las juderías, en la mayor parte de los reinos hispánicos, ocurrió en dicha etapa, entre las persecuciones de 1391 y el celo apostólico de las órdenes mendicantes de los años posteriores. En Teruel, como en otros lugares, se aceleró gracias a las predicaciones de san Vicente Ferrer ${ }^{123}$. En julio de 1415 el proceso de conversión masiva al cristianismo de los miembros de la aljama se había consumado hasta tal punto que los pocos que permanecían en la fe de sus mayores -in sua duricia persistentes- sufrían toda clase de vejaciones y agresiones, incluso por parte de sus antiguos hermanos en religión: magnis erumpnis, calamitatibus et contumeliis que cotidie inferuntur dictis iudeis, per illos qui vere lucis sole cognitotenebras iudaycas deposuerunt, et per multos alios christianos. El rey Fernando se veía por ello obligado a permitir la salida de cuantos quisieran abandonar la villa, llevándose consigo sus pertenencias, al par que les autorizaba a fijar su residencia allí donde lo tuviesen a bien ${ }^{124}$, mandando castigar con rigor a los que los ofendiesen: "por tal que somos informados $[\ldots]$ cuentra e ultra las ordinaciones por nos feytas, vexan e maltractan los judíos en diversas maneras ${ }^{125}$ ". Más tarde, y entorno a los años de la expulsión, los procesos inquisitoriales referidos a presuntos judaizantes ${ }^{126}$ han permitido que se conozcan los ritos y ceremonias practicados por los falsos conversos, así como sus argucias de ocultación, hechos que delatan las categorías de cristianos nuevos tras las represiones: criptojudíos, escépticos, dubitativos, sincréticos y cristianos auténticos, tal como señaló Julio Caro Baroja ${ }^{127}$.

\section{MARGINACIÓN MORAL}

Existía asimismo una marginación moral ${ }^{128}$. Vagabundos, hombres sin oficio, antiguos condenados, bastardos y a quien su comportamiento sexual era sancionado, dada la corrupción de las costumbres, según san Vicente: ja huy no s'i té ley: tot o volen tastar [los cristianos] hoc mores e juhyes, bèsties, hòmens ab hòmens; no y ha terme... gran culpa de todo ello venía de estar desocupado, ocioso, presto a la delin-

${ }^{122}$ López, La Corona de Aragón y el Magreb, p. 336-337; CuADRADA, La Mediterrània, cruïlla de mercaders, p. 247-259.

123 Vendrell, "La actividad proselitista de San Vicente Ferrer", p. 87-104.

124 ACA, Reg. 2394, f. 89v-90.

125 ACA, Reg. 2409, f. 89. Mi elipsis.

126 CAVAllero, "La temporalidad del lenguaje de la herejía", p. 11-35.

127 Caro Baroja, Los judios en la España moderna y contemporánea, I, p. 294-295; RÁBAde OBRAdó, "Expresiones de la religiosidad cristiana", p. 303-330.

128 Carrasco Manchado, Rábade Obradó (coord.), Pecar en la Edad Media. 
cuencia y al crimen ${ }^{129}$, como tan acertadamente señaló Geremek. En la mentalidad de la época estaba profundamente arraigada la idea de que sólo con el ejercicio de una profesión se legitimaba la situación del individuo en la sociedad y, entonces, se debía exigir a cada cual vivir de su trabajo. Por tanto, se condenaba con extremada dureza al inútil ${ }^{130}$, en palabras de Eiximenis:

negú no sia sofert en la comunitat que sia inútil, car axí com lo membre inútil en lo cos és mort e nou als vius, aixi aital hom que no és bo a res deu ésser gitat del cos civil de la comunitat així com a inútil [...] Hom ociós tostemps pensa mal, tostemps diu mal, tostemps fa mal, e provoca los altres a mal. E per tal, los bons regidors de la cosa pública deuen fort rependre e punir aquest vici, si volen que la cosa pública dure molt e stiga en pau; ne deuen perdonar a nengú que no el forcen d'exercitar en qualque honest treball, si doncs la persona no és aixi malalta que no puixe en res entendre.

Había una horda de burdeleros, rufianes ${ }^{131}$ y goliardos en los lugares de infamia, en lupanares, en recodos de caminos, cerca de los bosques. Cuando los pobres fueron asimilados a los jugadores, ladrones, bebedores y blasfemos, se les persiguió abiertamente, mediante vetos y bandos que se repetían año tras año, señal inequívoca que no alcanzaban el propósito deseado. Así, en Barcelona, en 1301, se proclamaba que ningún hombre osara tener tafureria de juego de día ni de noche en la ciudad ${ }^{132} \mathrm{y}$, pocos meses más tarde, se definía la transgresión:

$E$ es entès en tafureria tot loc en què hom tenga a loguer taulet o taulets, o postes $o$ altres coses cuvinents a jugar en plassa, o en cases, o en orts, o en carrera, e tot loc on hom prest a capsous o menys de capsous, sobre penyora o menys de penyora, e encara tot loc on hom tenga revenderia de vi contínument, e encara tot loc on hom juc contínuament ${ }^{133}$.

Por lo que respecta a las tabernas se declaraba:

Axí com Jesuchrist donà pastura als seus dexebles en la Església, axí lo dimoni done pastura als seus dexebles en la taverna, en van lla e embriaguen-se [...] tal persona que va a embriagar-se a la taverna, vet que és despullada de tots béns spirituals, e puix en infern està penjada, mas no pot morir, ab hun graffi al coll davall la barba. E diu que la mort li és pastura, ço és, que perpetualment estarà's en aquella pena, ultra les altres penes. Mas qua[n] tu te guardes de la taverna e vas a la església per combregar o rebre lo cors preciós de Jesuchrist, vet ací que és ovella de la pastura de Jesuchrist ${ }^{134}$.

129 Classen, Scarborough, Crime and Punishment in the Middle Ages; Geremer, Inutiles au monde, p. $9-11$.

130 EIXIMENIS, Regiment de la cosa publica, p. 124-125 y 130.

131 Gual Vilà, Justícia i terra, Armari II, calaix 4, doc. 23. Proceso en la curia de Verdú contra Joan Cases de Perpiñán, acusado de portar donas por lo món y anar divagant com a vagabundo. En sentencia del baile general de Poblet se le declara vagabundo y valido mendicant púbblic, concubinari y consuetudinari en delinquir. (26.04.1605).

132 AHCB, Llibre del Consell, I-1, f.9.

133 Ibidem, f.26v.

134 Mi elipsis. 
Se ordenó que no se pudiera jugar a gresca o con dinero en el cementerio de Santa Caterina o en la plaza de Santa Ana, en los portales, ni a gresca o a rifa -más adelante se añaden el palet y los bolos ${ }^{135}$ en ningún cementerio de la ciudad, ni en ningún otro lugar donde haya tafureria ${ }^{136}$, lugares que aumentan años más tarde, incluyendo tascas, carnicerías, cementerios y hospitales ${ }^{137}$; en 1314 se rehizo la prohibición, introduciendo una interesante distinción entre juegos buenos y malos: ne a gresca ne a riffa, ne altre joch de daus, sinó a taules o a escachs ${ }^{138}$. Según san Vicente jugar a dados és molt malvat pecat contra Déu [...] e en aquest joc se cometen molts mals ${ }^{139}$. Las multas y disposiciones sobre los blasfemos se mezclaban ahí mismo, como la del 1332, de jurar por Dios, por santa María o los santos a joch, ne en altra manera ${ }^{140}$. En opinión del dominico, la blasfemia y la utilización del nombre de Dios en vano por el pueblo deslenguado e insolente era un fenómeno previsible, indicador del fin de los tiempos, ya que antes no.l juraven ne.l specegaven [a Jesucristo] com ara fan los cristians. Què us diré? Que pigors són ara que infels. Se produce una identidad entre pecado, vicio y delito ${ }^{141}$. El mendigo, el pobre, para la buena circulación de la limosna, había de ser paciente, aceptar de buen grado la desgracia como camino de salvación, no desesperar ni murmurar contra Dios, quien había repartido los bienes en este mundo ${ }^{142}$. No envidiar a los ricos, no querer alzarse ni dominar, destrozando a los demás; si no se comportaba de esta guisa se convertía en un pobre orgulloso. El pauper superbus que era ya para san Agustín el "que se levanta orgullosamente contra los que poseen", creyendo que el reino de los cielos les era debido ${ }^{143}$. En el siglo XVI Juan Luís Vives dirá:

¿què cosa mas intolerable que un pobre sobervio? De èl dijo el sabio Hebreo: "Tres géneros de hombres aborreciò mi alma, y me lastimo muchísimo de la alma de ellos, el pobre sobervio, el rico engañador, y el viejo fatuo e insensato. A nadie aborrezcan, a ninguno envidien las cosas perecederas, ciñéndose y caminando apriesa para los inmortales, amen y serán amados, sean semejantes a Christo en la pobreza, e imitadores suyos en la caridad; los que puedan trabajar no estèn ociosos, que esto lo prohíbe el Discípulo de Christo Pablo $^{144} \ldots$

Las que sí entraban de lleno en el ámbito de la marginalidad eran las prostitutas ${ }^{145}$, fembres vils, àvols fembres, aunque la prostitución estuviese tolerada. En realidad

${ }_{135}$ AHCB, Llibre del Consell, I-12, f.21.

136 AHCB, Llibre del Consell, I-1, f.92v i 93v.

${ }_{137}$ AHCB, Llibre del Consell, I-12, f.18v.

${ }_{138}$ AHCB, Llibre del Consell, I-3, f.9v.

139 Mi elipsis.

${ }^{140}$ AHCB, Llibre del Consell, I-12, f.6.

141 Carrasco Manchado, "Sentido del pecado y clasificación de los vicios", p. 51-79.

142 Obviamente el pecado requería tanto su castigo religioso, cfr. TORRES JiMÉNEZ, "El castigo del pecado", p. 245-304; como también judicial (y pedagógico), cfr. BAZÁn DíAz, "La utilidad social del castigo", p. 447475 .

${ }^{143}$ Batany, Jean, "Les pauvres et la pauvreté", II, p. 470 y 484-485.

144 VIVEs, Juan Luís, Tratado del socorro de los pobres, p. 51-52.

${ }^{145}$ Gual VILÀ, Justícia i terra, Armari II, calaix 13, doc. 3: Pere Sales declara que días antes se encontró a una dona de seguida (prostituta), que el baile general tenía presa (1.01.1633). AP, Armari II, calaix 13, doc. 
una de las razones por las que las instituciones públicas habían de proteger la prostitución, entendida casi como una medida de beneficencia, era la de salvaguardar a la sociedad de males mayores, como la transgresión sexual con mujeres prohibidas, y otras, como señala Eiximenis:

Ara, és aixi que, jatsia que simple fornicació amb fembra pública sia gran pecat, així com damunt és dit, e tal que la llei de Déu puneix, emperò, per tal quant natura humana és tota corrompuda e inclinada a aquest pecat, en tant que si aquest pecat era punit per la senyoria present, seria en gran perill que los hòmens no fassen majors pecats, aixi com pecat d'adulteri e pecat contra natura, los quals són notables nocuments de la cosa pública; per tal, la senyoria dissimula aquest pecat de fornicació e el permet.

Zoofilia y homosexualidad que siempre se consideran desde la potencialidad masculina. Encontramos castigos ejemplares inferidos a hombres homosexuales. Muestra es el de Margalida, en 1460, en Valencia:

Com penjaren a Margalida; era hom. En l'any de 1460, dilluns, a 28 de joliol, en lo mercat de València, penjaren a Margalida, la que era home. E dient-li Miquel Borràs, fill de un notari de Mallorca, lo qual anava vestit com a dona, e estigué en moltes cases en València en hàbit e vestidures de dona, la qual cosa fonc sabuda e finc presa e turmentada. E per causa de la dita Margalida o Miquel foren presos alguns e turmentats. Emperò la dita Margalida fonc penjada e vestiren-li camisa de home, e ben curta, e sens panyos, en manera que amostrava bé totes ses vergonyes ${ }^{146}$.

Por todo lo dicho queda claro que el grupo formado por indigentes, vagabundos, gitanos, rateros, tahúres, brujas, alcahuetes y putas, era el que constituía la marginación por excelencia. Entre las ocupaciones deshonestas y viles que san Vicente recrimina, señala en primer lugar las que lo son por naturaleza: adevins, fetillers, usurers, dones del bordell, alcavots e rufians, y que, por lo tanto, dado que atentan en contra de Dios mismo, habían de prohibirse y ser perseguidos por los regidores urbanos. Además, había otras actividades que en algunos casos rompían la paz pública y la justicia, a veces podían ser peligrosas e ir en contra de la moralidad: canvistes, onzeners, taverners, hostalers e jugadors de daus, a los que se había de vigilar. Sería equivocado acusar a los marginados de todo movimiento revolucionario o de protesta, la masa no es una categoría social, nada más lejos que la imagen dicotómica de los pobres luchando contra los ricos. Cierto, la multitud es un grupo precario animado por emociones fugitivas y compuesto de elementos dispares. Es normal que los miembros de las clases dominantes dijeran que toda revuelta era plebeya, se resistían a confesar la realidad, la posibilidad para las personas perfectamente integradas de ceder a las emociones colectivas. Lo que no implica que los marginados se encontraran ausentes de la conflictividad social, al contrario. Estos grupos reafirmaban y canalizaban la fuerza y la violencia de los descontentos en la agresión a los poderosos. Pero no se

21: es fama pública que Cecília, viuda, de Vimbodí, done molt mal exemple a tot lo poble a vista de ses deshonestidats, (7.04.1681). López BeLtrán, "La prostitución consentida”, p. 145-170.

${ }^{146}$ Dietari del capellà, p. 125. 
trataba de una manifestación de unidad, sino de cohesión circunstancial. Sea como fuere, daban miedo.

\section{9. ÚLTIMAS CUESTIONES CONCEPTUALES}

Por razones obvias de economía de espacio estas conclusiones no serán excesivamente largas, menos aún repetitivas de lo dicho anteriormente. Mi única intención es la de resaltar el aspecto más importante y quizás más novedoso al cual creo haber llegado. He de empezar por el planteamiento inicial, la propuesta de analizar en dos bloques distintos otredad y marginación. Pienso que el esfuerzo realizado en la definición de los conceptos no ha sido en vano. Hace ya muchos años que Jacques Le Goff planteó una tipología de la marginalidad medieval y, aunque no se refería a fronteras nítidas, dado que los procesos de exclusión consienten a las personas y a los grupos cruzar de una categoría a otra, distinguía ${ }^{147}$ :

- los excluídos o los destinados a la exclusión: criminales, ladrones, bandidos, vagabundos, extranjeros, prostitutas, suicidas, heréticos;

- los despreciados: oficios "deshonestos" -carniceros, tintoreros, mercenarios- enfermos, pobres, mujeres, niños, viejos, bastardos;

- marginados propiamente dichos: desclasados -caballeros pobres-, locos, mendigos, usureros;

- los marginados imaginarios: las maravillas geográficas, los monstruos...

Le Goff puso en la palestra dos elementos: la marginación y la exclusión. Razonó sobre las bases ideológicas de la marginalidad, evidenciando que en general se trataba de controlar y/o excluir a los que parecían representar un peligro a la comunidad, una comunidad cerrada que debido a sus estructuras económicas, sociales y religiosas era una gran productora de marginados. El miedo a lo peligroso cristalizaba en base a algunas obsesiones, tales como la religión, la enfermedad, la identidad, el rechazo a la contra natura, la necesidad de estabilidad, y la ambivalencia hacia el valor del trabajo. Los procesos de marginación se producían a través de las etiquetas, los signos, los gestos y los rituales.

Es curioso que ni Le Goff ni sus colaboradores en el campo de lo que se ha llamado desde los años 70 del siglo pasado la antropología histórica, se plantearan nunca la distinción entre marginalidad y otredad. Parece como si el término Otro fuera de poca entidad o carente de interés, aún así, ha sido el constituyente esencial de la disciplina antropológica, su objeto de atención principal. Si repasamos la tipología de Le Goff y la confrontamos con la que he propuesto podemos darnos cuenta de las grandes diferencias existentes entre una y otra, a mi entender por no haber introducido la consideración de la alteridad, que trasloca, matiza y reajusta totalmente la categorización. En realidad el Otro es aquel o aquella que define en negativo mi mismidad, pero que no tiene por qué implicar siempre peligro. Incluso puede suscitar fascinación, o ambos sentimientos a la vez, como se dio con las mujeres, materializado en el movimiento

${ }^{147}$ Le Goff, "Les marginaux", p. 18-28. 
conocido como la Querelle des femmes, con sus defensores/as y detractores. Si incorporáramos el concepto de otredad a nuestros estudios podríamos, sin duda, matizar muchas de las erróneas dicotomías históricas en las que todavía nos movemos. Por otro lado, considero de imperiosa necesidad hacer el esfuerzo de fijar parámetros de análisis y discutir sobre ellos, como vehículo imprescindible de debate científico. Nuestra disciplina está aun carente de reflexión teórica, aspecto que contrasta con la grandísima riqueza de trabajos de archivo y descripciones históricas de rigor. Entre las problemáticas de la antropología histórica, en el 2008, Jean-Claude Schmitt ${ }^{148}$ señalaba la cuestión del parentesco, el estudio de los mitos, los ritos, los rituales y la litugia; e instaba a abrir nuevas vías, tales como la guerra y la paz, la venganza y el honor, la costumbre y el derecho. A mi entender esta aportación que presento podría ser una más de estas vías, siendo mi intención la de haber contribuído a sugerir, con la fundamentación documental suficiente, un abordaje distinto de los conceptos de marginalidad y otredad en la baja edad media, en un estudio que en ninguna instancia pretendo cerrado ni concluyente, al contrario.

\section{FUENTES}

Archivio di Stato di Bologna (ASBo).

Archivio di Stato di Prato, Archivio Datini, (ASP, AD).

Archivo de la Catedral de Barcelona (ACB).

Archivo de la Corona de Aragón (ACA).

Archivo Histórico de la ciudad de Barcelona (AHCB).

Cochon, Pierre, Chronique normande, edición Beaurepaire, Charles de, Rouen, Soc. Hist. Norm., 1876.

Dietari del capellà d'Alfons el Magnànim, edición MiralLes, Melcior, Valencia: Institució Alfons el Magnànim, 1988.

EIXIMENIS, Francesc, Libre apellat lo primer del Crestià, València: Lambert Partmart, 1483.

Eiximenis, Francesc, Dotzè del Crestià, WittuIn, Curt, et alii, editores, I y II, Gerona: Col·legi Universitari de Girona, Diputació de Girona, 1986-1987.

Eiximenis, Francesc, Lo libre de les dones, edición Naccarato, Frank, Barcelona, 1981.

Eiximenis, Francesc, Regiment de la cosa publica, edición Molins de ReI, Daniel de, Barcelona: Impremta Varias, 1927.

148 SCHмiтt, Jean-Claude, "Anthropologie historique”, disponible en: http://cem.revues.org/8862 [consultada 9.01.15]. 
Ferrer, sant Vicent, Sermons, edición de Sanchís Sivera, Josep, Barcelona, 19321971.

Florentinus, Antoninus, Summa Teologica, Venecia: apud Iuntas, 1582.

Guzmán, Francisco de, Decreto de Sabios, Alcalá, de Angulo, 1565.

Gual VILÀ, Valentí, Justícia i terra. La documentació de l'Arxiu de Poblet (Armari II), Valls: Cossetània edicions, 2003.

Llull, Ramon, Libre de Evast e Blanquerna, edición Galmés, Salvador, Barcelona, 1935-1954, 4 vols.

Medel Marchena, Ignacio, "Los caminos de la exclusión en la sociedad medieval: pecado, delito y represión. Recopilación bibliográfica", en López Ojeda, Esther (coord.), Los caminos de la exclusión en la sociedad medieval: pecado, delito y represión. XXII Semana de Estudios Medievales, Nájera, del 1 al 5 de agosto de 2011, Logroño: Instituto de Estudios Riojanos, 2012, p. 509-543.

MonteIL, Amans-Alexis, Histoire des Français des divers états. t. I et II: XIVe-XVe siècles, 4e edición LeCou, Victor, París: Imprimerie Guiraudet et Jouaust, 1853.

Novara, Filippo, Des quatre tens d'aage d'ome, edición FréVILle, Marcel de, Paris: SATF, 1888.

Proverbia Sententiaeque Latinitatis Medii Aevi, Walter, Hans (ed.), vol 4, Göttingen: Vandenhoeck \& Ruprecht, 1966.

Roserot, Alphonse, Le plus ancien registre des déliberations du conseil de ville Troyes, 1429-1433, Troyes: Dufour-Bouquot, 1886.

SAchetti, Franco, Sermoni Evangelici, Florencia: Le Monnier, 1857.

Simeoni, Luigi, "L'uficio dei forestieri a Bologna dal sec. XIV al XVI", en Atti e memorie della deputazione di storia patria per le provincie di Romagna, s. IV, XXV (1934-1935), pp. 71-95.

Usatges de Barcelona. El Codi mitjan segle XII, edición BASTARDAS, Joan, Barcelona: Fundació Noguera, 1984.

Vives, Juan Luís, Tratado del socorro de los pobres, Valencia: En la Imprenta de Benito Monfort, 1781.

vVAA, Actes municipals. 1358-1360, 2 (Col·lecció de documents de l'Arxiu Històric Municipal de Tarragona), Tarragona: Publicacions de l'Excm. Ajuntament de Tarragona, 1983.

VVAA, Actes municipals. 1369-1374-75, 3 (Col·lecció de documents de l'Arxiu Històric Municipal de Tarragona), Tarragona: Publicacions de l'Excm. Ajuntament de Tarragona, 1984.

vVAA, Actes municipals. 1378-79-1383-84, 4 (Col-lecció de documents de l'Arxiu Històric Municipal de Tarragona), Tarragona: Publicacions de 1'Excm. Ajuntament de Tarragona, 1985.

vVAA, Actes municipals. 1384-1385. 1385-1386, 5 (Col-lecció de documents de l'Arxiu Històric Municipal de Tarragona), Tarragona: Publicacions de 1'Excm. Ajuntament de Tarragona, 1986. 
vVAA, Actes municipals. 1386-1387. 1387-1388, 6 (Col-lecció de documents de l'Arxiu Històric Municipal de Tarragona), Tarragona: Publicacions de l'Excm. Ajuntament de Tarragona, 1987.

vVAA, Actes municipals. 1388-1389. 1393-1395, 7 (Col-lecció de documents de l'Arxiu Històric Municipal de Tarragona), Tarragona: Publicacions de l'Excm. Ajuntament de Tarragona, 1988.

vVAA, Actes municipals. 1397-1399. 1399-1400, 8 (Col-lecció de documents de l'Arxiu Històric Municipal de Tarragona), Tarragona: Publicacions de l'Excm. Ajuntament de Tarragona, 1991.

\section{BIBLIOGRAFÍA}

Ariès, Philippe, L'Enfant et la vie familiale sous l'Ancien Régime, París: Plon, 1960. Ariès, Philippe, "La infancia", Revista de Educación, 281 (1986), p. 5-17.

Asenjo González, María, "Integración y exclusión. Vicios y pecados en la convivencia urbana", en CARRASco Manchado, Ana Isabel, RÁbade Obradó, María del Pilar (coord.), Pecar en la Edad Media, Madrid: Sílex ediciones, 2008, p. 185- 207.

Armenteros Martínez, Iván, La esclavitud en Barcelona a fines de la Edad Media (1479-1516). El impacto de la primera trata atlàntica en un mercado tradicional de esclavos, tesis doctoral, Universidad de Barcelona, 2012. Disponible en: http:// www.tdx.cat/handle/10803/95887 [Consultada 27.12.14].

Batany, Jean, "Les pauvres et la pauvreté dans les états du monde", en Mollat, Michel (dr.), Études sur l'histoire de la pauvreté. (Moyen Age-XVIe siecle). París: Publications de la Sorbonne, 1974, 2 vols.

BAZÁn DíAZ, Iñaki, "La utilidad social del castigo del delito en la sociedad medieval: 'para en exemplo, terror e castygo de los que lo ovyesen'", CARRASCo Manchado, Ana Isabel, RÁbade Obradó, María del Pilar (coord.), Pecar en la Edad Media, Madrid: Sílex ediciones, 2008, p. 447-475.

BÉRIAC, Françoise, Histoire des lépreux au Moyen-Âge, une société d'exclus, Paris: Imago, 1988.

Blasco Martínez, Asunción, "Razones y consecuencias de una decisión controvertida: la expulsión de los judíos de España en 1492", Kalakorikos: Revista para el estudio, defensa, protección y divulgación del patrimonio histórico, artístico y cultural de Calahorra y su entorno, $\mathrm{n}^{\circ} 10,2005$, p. 9-36.

Blasco Martínez, Asunción, "Los judíos del Reino de Aragón: encuentros y desencuentros de una comunidad marginada", Revista de la CECEL, $\mathrm{n}^{\circ} 1,2000$, p. 121-158.

Blasco Martínez, Asunción, "Los judíos y su expulsión”, en Centellas Salamero, Ricardo (coord.), Ferdinandus Rex Hispaniarum: príncipe del renacimiento, Zaragoza, 2006, p. 329-338. 
Burke, Peter, What is cultural history?, Cambridge: Malden, 2008.

Burke, Peter, Hibridismo cultural, Madrid: Akal universitaria, 2010.

CADUFF, Claudia, "I 'publici latrones' nella città e nel contado di Firenze a metà Trecento", Ricerche storiche, 18 (1988), p. 514-516.

Cantera Montenegro, Enrique, "La imagen del judío como prototipo del mal en la Edad Media", en Carrasco Manchado, Ana Isabel, Rábade Obradó, María del Pilar (coord.), Pecar en la Edad Media, Madrid: Sílex ediciones, 2008, p. 297- 326.

Caro Baroja, Julio, Los judios en la España moderna y contemporánea, Madrid: Ediciones AKAL, 1978, 3 vols.

Carrasco Manchado, Ana Isabel, "Sentido del pecado y clasificación de los vicios", en LóPEz OJEDA, Esther (coord.), Los caminos de la exclusión en la sociedad medieval: pecado, delito y represión, XXII Semana de Estudios Medievales. Nájera, del 1 al 5 de agosto de 2011, Logroño: Instituto de Estudios Riojanos, 2012, p. 51-79.

Carrasco Manchado, Ana Isabel, Rábade Obradó, María del Pilar (coord.), Pecar en la Edad Media, Madrid: Sílex ediciones, 2008.

CAstaño González, Javier, "Las aljamas judías de Castilla a mediados del siglo XV: la Carta Real de 1450”, En la España Medieval, 18 (1995), p. 181-203.

Cavallero, Constanza, "La temporalidad del lenguaje de la herejía. El caso de la construcción de la herejía judaizante en el ocaso de Edad Media", Medievalismo, 22 (2012), p. 11-35.

Cherubini, Giovanni, "Appunti sul brigantaggio in Italia alia fine del Medioevo", en Studi di storia médiévale e moderna per Ernesto Sestan, Firenze: Raveggi, 1980, vol. I, p. 103-133.

Cherubini, Giovanni, "I lavoratori fiorentini della lana fra solidarietà di mestiere e primo capitalismo", Cofradías, gremios, solidaridades en la Europa medieval, XIX Semana de Estudios Medievales de Estella, Pamplona: Gobierno de Navarra, 1993, p. 101-112.

Classen, Albrecht, Scarborough, Connie (eds.), Crime and Punishment in the Middle Ages and Early Modern Age. Mental-Historical Investigations of Basic Human Problems and Social Responses, Berlin/Boston: Walter de Gruyter GmbH, 2013.

Córdoba de la Llave, Ricardo, "Marginación social y criminalización de las conductas", Medievalismo, 13-14 (2004), p. 293-322.

Córdoba de la Llave, Ricardo, "Los caminos de la exclusión en la sociedad medieval: pecado, delito y represión. La Península Ibérica (ss. XIII y XVI)”, en López Ojeda, Esther (coord.), Los caminos de la exclusión en la sociedad medieval: pecado, delito y represión. XXII Semana de Estudios Medievales, Nájera, del 1 al 5 de agosto de 2011, Logroño: Instituto de Estudios Riojanos, 2012, p. 13-50.

Córdoba de la Llave, Ricardo, "Conflictividad social en los reinos hispánicos durante la Baja Edad Media. Aproximación historiográfica", Vínculos de Historia, $\mathrm{n}^{\circ} 3$ (2014), p. 34-53. 
Covey, Herbert C., "People with leprosy (Hansen's disease) during the Middle Ages", The Social Science Journal, 38 (2001), p. 315-321.

Coyecque, Ernest, L'Hôtel-Dieu de Paris au Moyen âge. t. I, Paris: H. Champion, 1889.

CuAdrada, Coral, El Maresme Medieval: Hàbitat, Economia i Societat, segles X-XIV, Mataró: Caixa d'Estalvis Laietana, 1988.

CUADRADA, Coral, "Sobre les relacions camp-ciutat a la Baixa Edat Mitjana: Barcelona i les comarques de l'entorn", Acta/Mediaevalia, 11-12 (1990-1991), p. 161-185.

CuAdrada, Coral, "Esclaus i esclaves a la Baixa Edat Mitjana: els diferents destins de canvi de vida", De l'esclavitud a la llibertat. Esclaus i lliberts a l'Edat Mitjana, Actas del Coloquio Internacional celebrado en Barcelona del 27 al 29 de mayo de 1999, Barcelona: CSIC, 2000, p. 325-340.

CUADRADA, Coral, La Mediterrània, cruilla de mercaders, Barcelona: Rafael Dalmau editor, 2001.

Cuadrada, Coral, "Pobresa, marginació i sexe a l'edat mitjana", en PIÑol, Daniel (coord.), La història dels altres. Exclusió social i marginació a les comarques tarragonines (segles XIII-XX). Tarragona, Publicacions del Cercle d'Estudis Històrics i Socials Guillem Oliver, 2003, p. 21-41.

Cuadrada, Coral, El llibre de la pesta. Barcelona, Rafael Dalmau editor, 2012.

Dean, Trevor, Crime in Medieval Europe, New York: Routledge, 2001.

Delumeau, Jean, La peur en Occident, París: Pluriel, 1978.

Del Val Valdivieso, $\mathrm{M}^{\mathrm{a}}$ Isabel, "La historia de la mujer medieval en la actualidad: fortalezas y debilidades”, en Solórzano Telechea, Jesús Ángel; Arízaga BolumBuru, Beatriz; Aguiar Andrade, Amélia, (coords.), Ser mujer en la ciudad medieval europea, 2013, p. 19-40.

Duby, Georges, Guillermo el Mariscal, Madrid: Alianza, 1997.

EBNER, Herwig, "Der Bauer in der mittelalterlichen Historiographie" en Bäuerliche Sachkultur des Spätmittelalters, Viena: Österreichisches Akademie der Wissenschaften Ph hist Klasse, Sitzungsber, 439, 1984.

EchevarRía Arsuaga, Ana, "Los mudéjares: ¿minoría, marginados o 'grupos culturales privilegiados'?", Medievalismo, 18 (2008), p. 45-65.

Escobar CAmacho, José Manuel, "La pobreza: de virtud a vicio. La práctica de la caridad en la Baja Edad Media", en López OJeDA, Esther (coord.), Los caminos de la exclusión en la sociedad medieval: pecado, delito y represión, XXII Semana de Estudios Medievales. Nájera, del 1 al 5 de agosto de 2011, Logroño: Instituto de Estudios Riojanos, 2012, p. 109-144.

Evangelisti, Paolo, La costruzione di uno stato. Linguaggi politici, valori identitari, progetti di governo in area catalano-aragonese, Milán: Editrice Francescane, 2006.

Eyler, Joshua R., Disability in the Middle Ages: Reconsiderations and Reverberations, Aldershot: Ashgate Publishing, 2013. 
Ferrer i Mallol, Ma Teresa, Mutgé i Vives, Josefina (eds.), De l'esclavitud a la llibertat. Esclaus i lliberts a l'Edat Mitjana, Barcelona, 2000.

Fontana, Josep, Europa ante el espejo, Madrid: Crítica, 1994.

FouCAult, Michel, Vigilar y castigar, nacimiento de la prisión, Madrid: Siglo XXI, 2002.

Freedman, Paul, The Origins of Peasant Servitude in Medieval Catalonia, Cambridge, Eng.: Cambridge University Press, 1991.

Gallent Marco, Mercedes, "La asistencia sanitaria a los marginados en la Edad Media", Clio \& Crimen, no 9 (2012), p. 135-164.

García Fitz, Francisco, "Las minorias religiosas y la tolerancia en la Edad Media hispánica: ¿mito o realidad?”, en GarCíA SANJuÁN, Alejandro (coord.), Tolerancia y convivencia étnico-religiosa en la Península Ibérica durante la Edad Media: III Jornadas de Cultura Islámica, Huelva: Universidad de Huelva, 2003.

García Herrero, María del Carmen, "Las etapas de la vida", Medievalismo: Boletín de la Sociedad Española de Estudios Medievales, 13-14 (2004), p. 29-48.

GazzinI, Marina, a cura di, Studi confraternali: orientamenti, problemi, testimonianze, Firenze University Press, 2009.

Geremer, Bronislaw, La main d'oeuvre salariée dans l'artisanat parisien du XIIIe au XVe siècle. Étude du marché de la main d'oeuvre au Moyen Âge. París-La Haye: Mouton, 1968.

GEREMEK, Bronislaw, "La popolazione marginale tra il medioevo e l'era moderna", Studi Storici, 9 (1968), p.623-640.

Geremer, Bronislaw, Les marginaux parisiens aux XIVe et XVe siècles, París: Flammarion 1976.

GerEMEK, Bronislaw, Inutiles au monde. Truands et misérables dans L'Europe Moderne 1350-1600, París: Gallimard, 1980.

GEREMEK, Bronislaw, Le salariat dans l'artisanat parisien aux XIIIe-XVe siècles. Étude sur le marché de la main-d'oeuvre au moyen âge, Paris: École des Hautes Etudes en Sciences Sociales-Mouton, 1982.

GEREMEK, Bronislaw, La potence ou la pitié. L'Europe et les pauvres du Moyen Age à nos jours, París: Gallimard, 1987.

GeremeK, Bronislaw, "Le marginal", en Le Goff, Jacques (dr.), L’homme médiéval, París: Seuil, 1989.

GonzÁlez Betlinski, Margarida, Vinyoles Vidal, Teresa Maria, "Els infants abandonats a les portes de l'hospital de Barcelona (anys 1426-1439)", en Riv, Manuel, et alii, La pobreza y la asistencia a los pobres en la Cataluña medieval. Volumen misceláneo de estudios y documentos, II, Barcelona, 1981-1982, p. 191-285.

GónZaLEZ de Fauve, María Estela, "Medicina y sociedad en la época de 'El Quijote"”, Cuadernos de Historia de España, 80, (2006), p. 205-211.

Graus, Frantisek, "Randgruppen der städtischen Gesellschaft in Spätmittelalter", en Zeitschrift für Historische Forschung, Berlin: Duncker \& Humblot, 1981. 
GuEsLin, André, D'ailleurs et de nulle part: Mendiants, vagabonds, clochards, SDF en France depuis le Moyen Age, París: Fayard, 2013.

Guillén, Fabienne P., Trabelsi, Salah (eds.), Les esclavages en Méditerranée. Espaces et dynamiques économiques. Casa de Velázquez, Madrid, 2012.

Hernando, Josep, “Tractatus Adversus Iudaeos. Un tratado anónimo de polémica antijudía (s. XIII), Acta/Mediaevalia, 7-8 (1986), p. 9-77.

Hernando, Josep, "L'estat físic dels esclaus: malalties i defectes. La redhibició i l'evicció i la compravenda d'esclaus (s. XIV-XV)", Acta/Mediaevalia, 23-24 (2002), p. 415-439.

Hilton, Rodney, Bond Men Made Free. Medieval Peasant Movements and the English Rising of 1381, Viking Press, 1973.

Homet, Raquel, Los viejos y la vejez en la Edad Media. Sociedad e imaginario, Buenos Aires: Pontificia Universidad Católica Argentina, 1997.

Hinojosa Montalvo, José Ramón, "Los judíos en la España medieval: de la tolerancia a la expulsión", en MARTínez SAN Pedro, María Desamparados, Los marginados en el mundo medieval y moderno. Almería, 5 a 7 de noviembre de 1998, 2000, Alicante: Universidad de Alicante, p. 25-41.

Hinojosa Montalvo, José Ramón, "Las comunidades judías valencianas a finales de la Edad Media: las vísperas del exilio", Revista de la CECEL, n 1, 2000, p. 80104.

Hinojosa Montalvo, José Ramón, "Propiedad y nivel de riqueza", en Adao De FonSECA, Luis, et alii (coords.), Os reinos ibéricos na Idade Média: libro de homenagem ao profesor doutor Humberto Carlos Baquero Moreno, Porto: Livraria Civilização, I, 2003, p. 677-686.

HüGLI, Hilde, Der deutsche Bauer im Mittelalter dargestellt nach dem deutschen literarischen Quellen vom 11-15 Jahrundert, Berna: P. Haupt, 1929.

Ivars, Andrés, El escritor Fr. Francisco Eximénez en Valencia (1383- 1408), edición de Santonja, Pedro, Benissa, Ayuntamiento de Benissa: Comisión de Cultura, 1989 [ $1^{\text {a }}$ ed. 1920-1926].

Jösт, Erhard, Bauernfeindlichkeit Die Historien des Ritters Neithart Fuchs Göttingen: Kümmerle, 1976.

Kriegel, Maurice, Les juifs à la fin du Moyen Age dans l'Europe Méditerranéenne, París: Hachette, 1979.

LAdERo, Miguel Ángel, "Grupos marginales", en AAVV, La Historia Medieval en España. Un balance historiográfico (1968-1998) [XXV Semana de Estudios Medievales, Estella, 14-18 de julio de 1998), Pamplona: Gobierno de Navarra, Departamento de Educación y Cultura, p. 505-601.

LE Goff, Jacques, "Les marginaux dans l'Occident médiéval", en VVAA, Les marginaux et les exclus dans l'histoire, París: U.G.E., 1979, pp. 18-28.

Little, Lester K., Religious Poverty and the Profit Economy in Medieval Europe, Londres: P. Elek, 1978. 
Lluch Bramon, Rosa, Els remences. La senyoria de l'Almoina de Girona als segles XIV $i$ XV, Girona: Associació d'Història Rural de les Comarques Gironines, Centre de Recerca d'Història Rural (ILCG-Secció Vicens Vives) de la Universitat de Girona y Documenta Universitaria, 2005.

LoOIJESTEIJN, Henk, "Funding and funding private charities: Leiden almshouses and their founders, 1450-1800", Continuity and Change, 2012, vol. 27 (2), p. 199-239.

López Alonso, Carmen, La pobreza en la España medieval. Estudio histórico-social, Madrid: Ministerio de Trabajo y Seguridad Social, 1986.

López Beltrán, María Teresa, "La prostitución consentida y la homosexualidad reprimida", en LÓPEz OJEDA, Esther (coord.), Los caminos de la exclusión en la sociedad medieval: pecado, delito y represión, XXII Semana de Estudios Medievales. Nájera, del 1 al 5 de agosto de 2011, Logroño: Instituto de Estudios Riojanos, 2012, p. 145-170.

LóPez Pérez, M. Dolores, La Corona de Aragón y el Magreb en el siglo XIV (13311410), Barcelona: CSIC, 1995.

LÓPEZ OJEDA, Esther (coord.), Los caminos de la exclusión en la sociedad medieval: pecado, delito y represión, XXII Semana de Estudios Medievales. Nájera, del 1 al 5 de agosto de 2011, Logroño: Instituto de Estudios Riojanos, 2012.

Martínez García, Luis, "Pobres, pobreza y asistencia en la Edad Media hispana. Balance y perspectivas", Medievalismo: Boletín de la Sociedad Española de Estudios Medievales, 18 (2008), p. 67-108.

Martínez, Tomàs, Micó, Isabel, "Els pobres a la literatura catalana medieval", Boletín de la Sociedad Castellonense de Cultura, 67 (1991), p. 25-66.

Marzal Palacios, Francisco Javier, La esclavitud en Valencia durante la Baja Edad Media (1375-1425), tesis doctoral, Universidad de Valencia, 2006. Disponible en: http://www.tdx.cat/bitstream/handle/10803/9996/marzal.pdf;jsessionid=AE51222 BC25C039A38C82E8D4320FBE2.tdx1?sequence=1 [consultada 27.12.14].

Miedema, Hessel, "Realism and Comic Mode The Peasant", Simiolus, 9/4 (1977), p. 205-219.

MinoIs, Georges, Historia de la vejez, Madrid: Narcea, 1987.

Mitre Fernández, Emilio, "Historia y marginación. Mundos desvelados y mundos por desvelar (Un modelo especialmente aplicable al Medievo)", en GonzáLez MíNGUEz, César, BAZÁn, Iñaki, Reguera, Iñaki (eds.), Marginación y exclusión social en el País Vasco, Bilbao, 2000, p. 13-24.

Mitre Fernández, Emilio, "Otras religiones ¿otras herejías? (El mundo mediterráneo ante 'el choque de civilizaciones'? en el Medievo)", En la España Medieval, 25 (2002), p. 9-45.

Mitre Fernández, Emilio, Iglesia, herejía y vida política en la Europa medieval, Madrid: Biblioteca de Autores Cristianos, 2007.

Mitre Fernández, Emilio, "Sobre la difícil delimitación de un campo: la herejía en Europa del pleno medievo", en Castellano, Juan Luis, López-Guadalupe Muñoz, 
Miguel Luís (coords.), Homenaje a Antonio Domínguez Ortiz, Granada: Universidad de Granada, 2008, I, p. 655-668.

Mitre FernÁndez, Emilio, "Al margen del valdismo y del catarismo: religiosidades "desviadas" y movimientos populares del Occidente (Panorama histórico y elenco bibliográfico)", Norba. Revista de Historia, na 21 (2008), p. 181-203.

Mitre Fernández, Emilio, "El enclave hereje de la sociedad: el 'otro' cristiano entre la teología y la moral", en LóPEz OJEDA, Esther (coord.), Los caminos de la exclusión en la sociedad medieval: pecado, delito y represión, XXII Semana de Estudios Medievales. Nájera, del 1 al 5 de agosto de 2011, Logroño: Instituto de Estudios Riojanos, 2012, p. 225-244.

Mitre Fernández, Emilio, Ciudades medievales europeas. Entre lo real y lo ideal, Madrid: Cátedra, 2013.

Mollat, Michel, Les pauvres au Moyen Age, París: Hachette, 1978.

Monsalvo Antón, José Ma " "El enclave infiel: el ideario del 'otro' judío en la cultura occidental durante los siglos XI al XIII y su difusión en Castilla", en LóPEZ OJEDA, Esther (coord.), Los caminos de la exclusión en la sociedad medieval: pecado, delito y represión, XXII Semana de Estudios Medievales. Nájera, del 1 al 5 de agosto de 2011, Logroño: Instituto de Estudios Riojanos, 2012, p. 171-223.

Monteira Arias, Inés, Muñoz Martínez, Ana Belén, Villaseñor Sebastián, Fernando, Relegados al margen. Marginalidad y espacios marginales en la cultura medieval, Madrid: CSIC, 2009.

Montes Romero-Camacho, Isabel, "Judíos y mudéjares", Medievalismo, 13-14 (2004), p. 241-274.

Moxey, Keith, Peasants Warriors and Wives Popular Imagery in the Reformatio, Chicago: The University of Chicago Press, 1987.

Muldoon, James, Popes, Lawyers and Infidels: The Church and the Non-Christian World, 1250-1550, Filadelfia: University of Pensylvania Press, 1979.

Narbona Vizcaíno, Rafael, "Las leyes de pobres en la metròpolis. Mendigos, miserables, trabajadores en Valencia, 1306-1462", Clio \& Crimen, no 9 (2012), p. 165-284.

Neveux, François, "Les marginaux et le clergé dans la ville et le diocèse de Bayeux au XIVe et XVe siècles", Cahier des Annales de Normandie, Marginalité, déviance et pauvreté en France (XIVe-XIXe siècles), 13 (1981), p. 17-41.

OrIGO, Iris, "The domestic enemy, Eastern slaves in Tuscany in the fourteenth and fifteenth centuries", Speculum, XXX/3 (1955), p. 321-366.

Pagden, Anthony, The fall of Natural Man: The American Indian and the Origins of Comparative Ethnology, Cambridge: Cambridge University Press, 1982.

Pérez de Tudela y Velasco, María Isabel, "Ancianidad, viudedad... El hombre medieval en su edad postrera", en De La Iglesia Duarte, José Ignacio, La familia en la Edad Media. XI Semana de Estudios Medievales, Nájera 31 julio-4 agosto 2000, 2001, p. 285-316. 
PIÑEYRÚA, Alejandra, "Caridad cristiana, asistencia social y poder político: las instituciones hospitalarias en España (siglos XIII al XVI)", en GonZÁleZ DE FAUve, María Estela (ed.), Ciencia, poder e ideología. El saber y el hacer en la evolución de la medicina española (siglos XIV-XVIII), Buenos Aires: Instituto de Historia de España "Claudio Sánchez Albornoz", Facultad de Filosofía y Letras, Universidad de Buenos Aires, 2001, p. 61-107.

PINTO, Giovanni, "Un vagabondo, ladro e truffatore nella Toscana della seconda metà del '300: Sandro di Vanni detto Pescione”, Ricerche storiche, 4 (1974), p. 327-345.

Prat i Carós, Joan, "Estigma“, en Ascensión Barañano (coord..), Diccionario de relaciones interculturales: diversidad y globalización, Madrid: Editorial Complutense, 2007, pp. 124-128.

Quaglioni, Diego, Esposito, Anna, "I processi contro gli ebrei di Trento, 1475", en Maire-Vigueur, Jean Claude, Paravicini-Bagliani, Agostino (drs.), La parola all'accusato, Palermo: Sellerio, 1991.

RÁbade Obradó, Ma del Pilar, "Expresiones de la religiosidad cristiana en los procesos contra los judaizantes del tribunal de Ciudad Real/Toledo, 1483-1507", En la España Medieval, 13 (1990), p. 303-330.

RAUPP, Hans-Joachim, Bauernsatiren; Entstehung und Entwicklung des bäuerlichen Genres in der deutschen und niederländischen Kunst ca. 1470-1570, Niederzier: Lukassen, 1986.

RHEINHEIMER, Martín, Pobres, mendigos y vagabundos: la supervivencia en la necesidad 1450-1850, Madrid: Siglo XXI, 2009.

Rubio Vela, Agustín, "La asistencia hospitalaria infantil en la Valencia del siglo XIV: pobres, huérfanos y expósitos", Dynamis 2, (1982), p. 159-191.

Rubio Vela, Agustín, “Infancia y marginación. En torno a las Instituciones trecentistas valencianas para el socorro de huérfanos", Revista d'història medieval, 1 (1990), p. 111-153.

SABATÉ, Flocel, La feudalización de la sociedad catalana, Granada: Universidad de Granada, 2007.

SABATÉ, Flocel, (ed.), Hybrid identities, Berna : Peter Lang, 2014.

SABATÉ, Flocel, (ed.), Identities on the move, Berna : Peter Lang, 2014.

SAlRaCh, Josep M., "La pesta negra i els orígens del problema remença", Anuario de Estudios Medievales, Annex 24: Pere el Cerimoniós i la seva época, Barcelona: CSIC, 1989, p. 13-34.

Salrach, Josep M., La fam al món. Passat i present, Vic: Eumo editorial, 2009.

SAS van DAmme, Astrid de, "El Amarillo en la Baja Edad Media. Color de traidores, herejes y repudiados", Estudios Medievales Hispánicos, 2 (2013), p. 241-276.

Sснміт, Jean-Claude, "Anthropologie historique", Bulletin du centre d'études médiévales d'Auxerre, BUCEMA, Hors-série $\mathrm{n}^{\circ} 2$ (2008), disponible en: http://cem. revues.org/8862 [consultada 9.01.15]. 
ShohAm-Steiner, Ephraim, On the Margins: Leprosy, Madness, and Disability among the Jews of Medieval Europe, Detroit: Wayne State University Press, 2014.

Stella, Alessandro, La révolte des Ciompi. Les hommes, les lieux, les travail. París: Éditions de l'École des Hautes Études en Sciences Sociales, 1993.

To Figueras, Lluís, Família i hereu a la Catalunya nord-oriental (segles X-XII), Barcelona: Publicacions de l'Abadia de Montserrat, 1997.

ToRres JimÉnEZ, Raquel, "El castigo del pecado: excomunión, purgatorio, infierno" en Carrasco Manchado, Ana Isabel, Rábade Obradó, María del Pilar (coord.), Pecar en la Edad Media, Madrid: Sílex ediciones, 2008, p. 245-304.

VALDEÓN, Julio, "El ritmo del individuo: en las puertas de pobreza, de la enfermedad, de la vejez, de la muerte", en De La Iglesia Duarte, José Ignacio, La vida cotidiana en la Edad Media. VIII Semana de Estudios Medievales. Nájera 4-8 agosto 1977, p. 275-288.

VAuChez, André, "Assistance et charité en Occident, XIIIe-XVe siècles", en BARBAgli Bagnoli, Vera (ed.), Domanda e Consumi. VI Settimana de l'Istituto di Storia Economica Francesco Datini, Florencia: Le Monnier, 1978.

VendRell, Francisca, "La actividad proselitista de San Vicente Ferrer durante el reinado de Fernando I de Aragón”, Sefarad, XIII (1953), p. 87-104.

vVAA, Assistenza e Solidarietà in Europa. Secc. XIII-XVIII. Atti della "Quarantaquattrosima Settimana di Studi" edición CAVACIOCCHI, Simonetta, Florencia: Firenze University Press, 2013.

vVAA, Schiavitù e servaggio nell'economia europea. Secc. XIII-XVIII. Atti della "Quarantacinquesima Settimana di Studi”, edición CAVACIOCCHI, Simonetta, Florencia: Firenze University Press, 2014. 